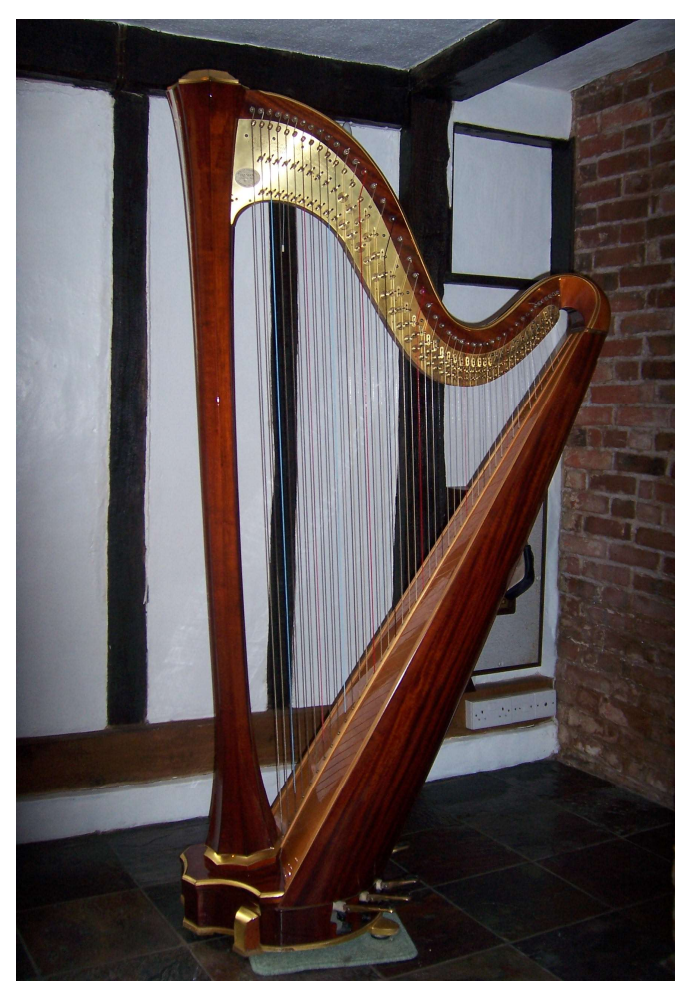

\section{Effects of humidity on natural gut harp strings}

Nicolas Lynch-Aird \& Jim Woodhouse

lynchaird@yahoo.co.uk

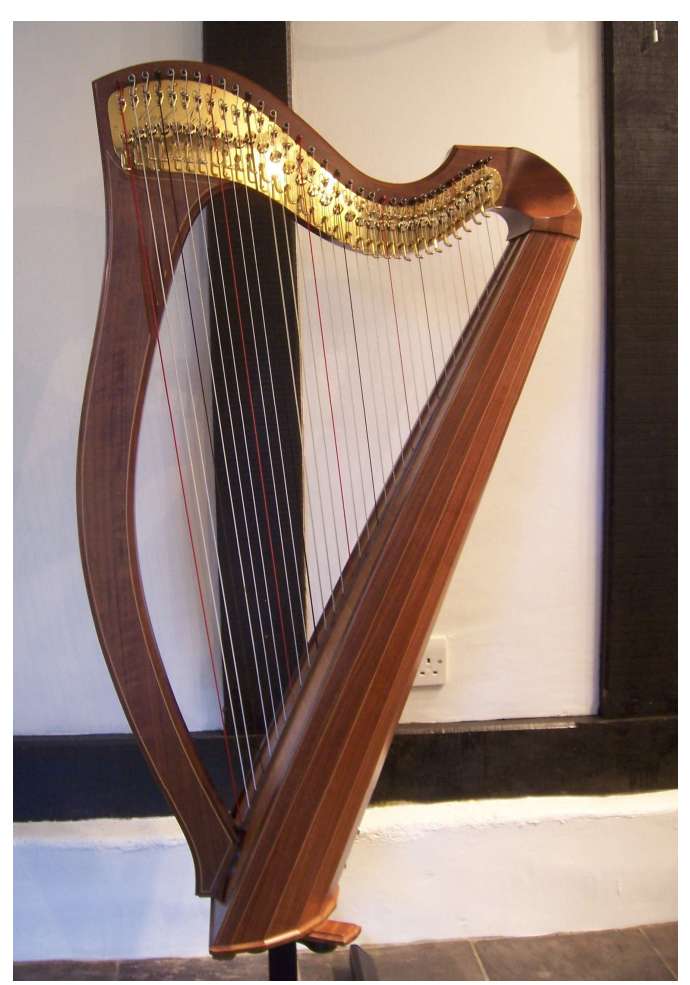

Mark Norris Lute-Back lever harp 


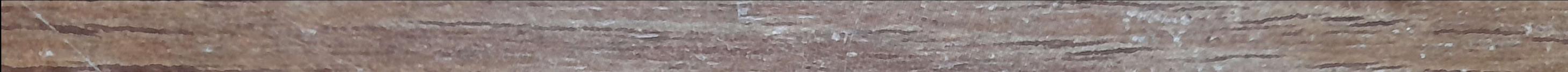

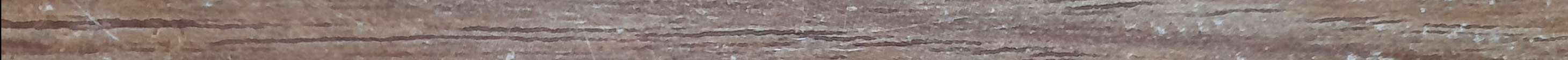

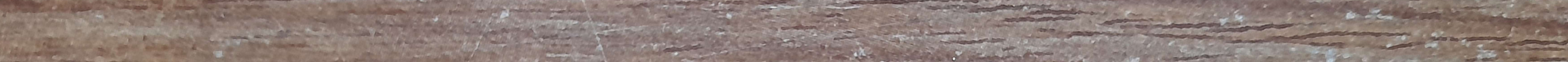

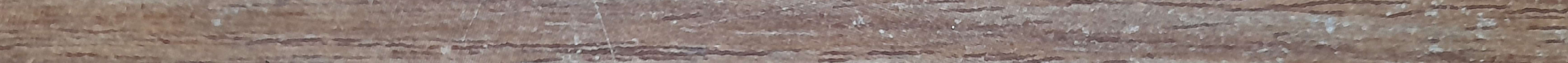

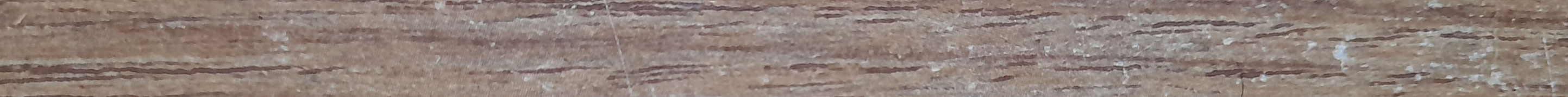

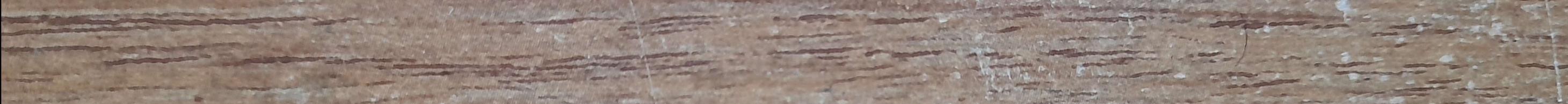

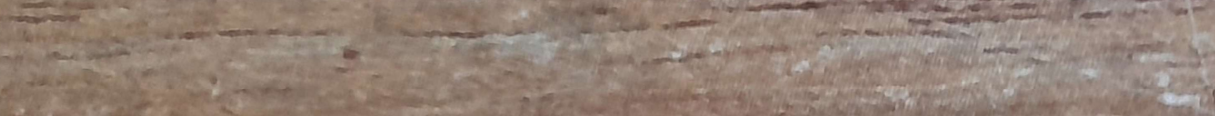

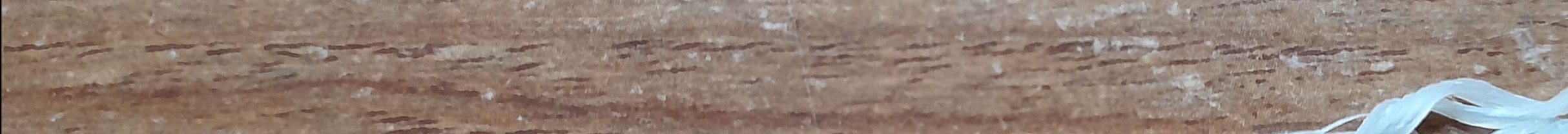

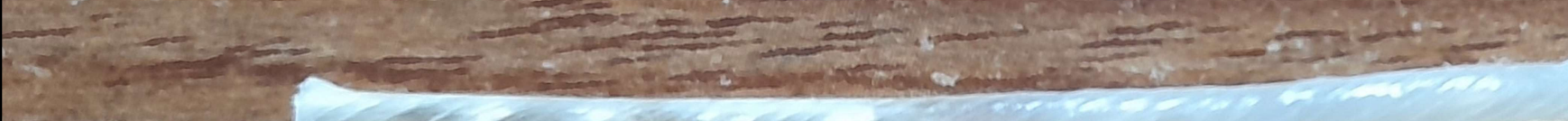

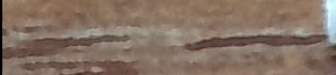

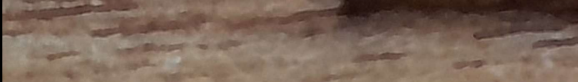

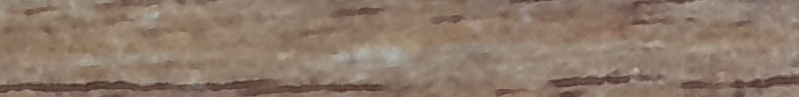

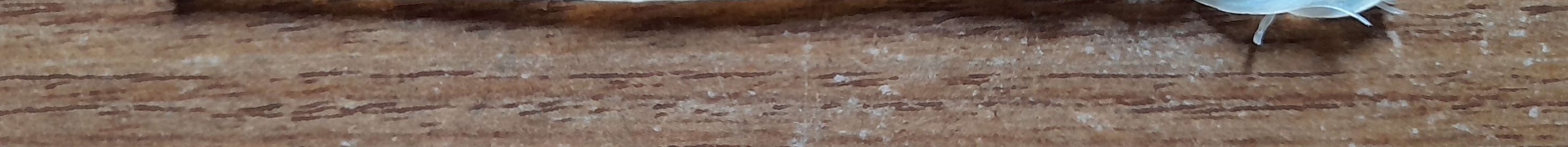

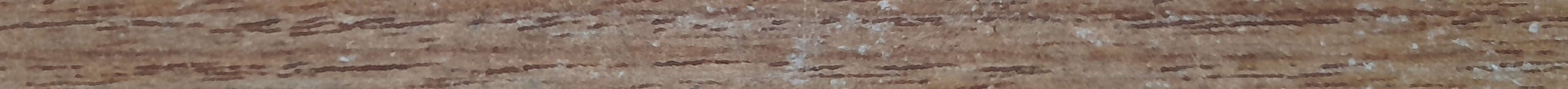

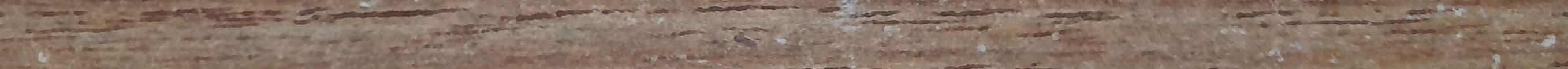

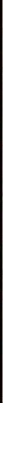




\section{Soaked section has visibly swollen}

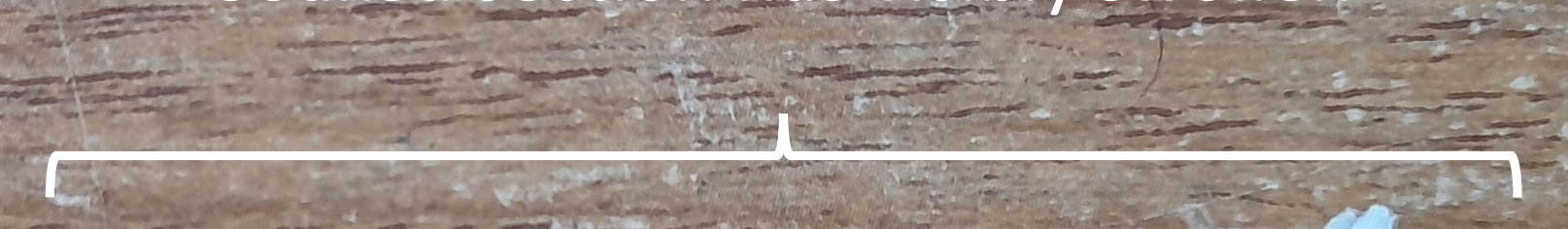

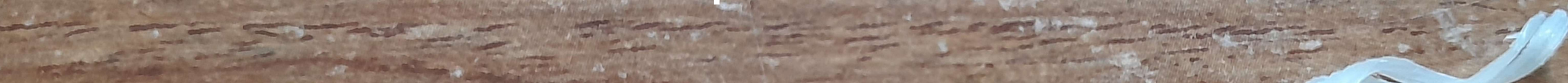

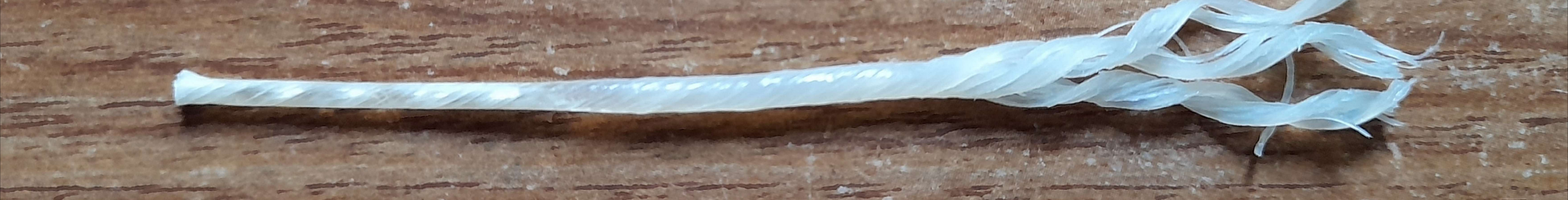

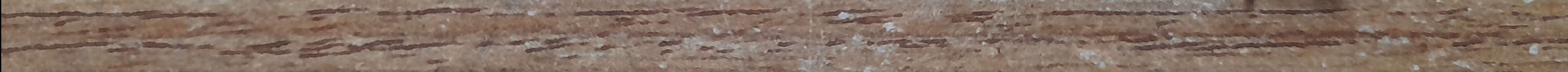

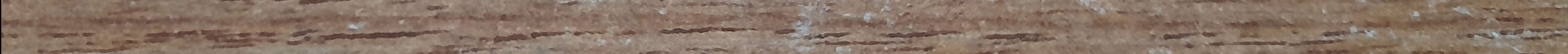

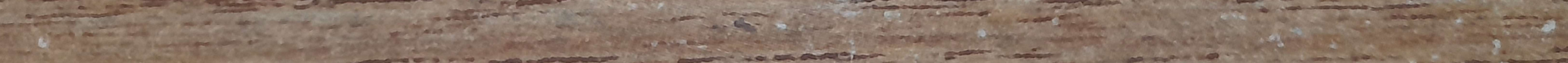

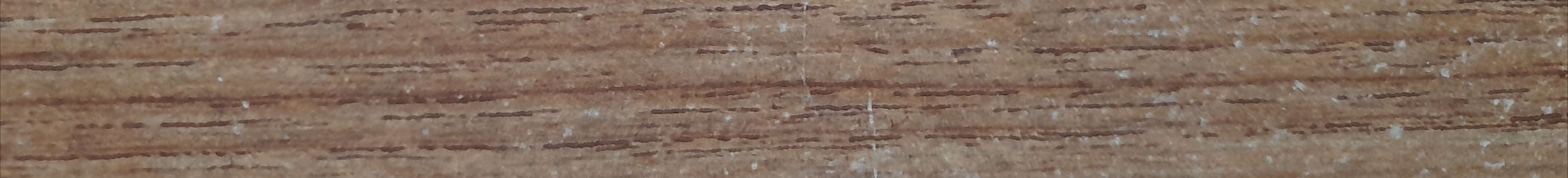


Twist Angle =

Arctan (Circumference / Twist Period)

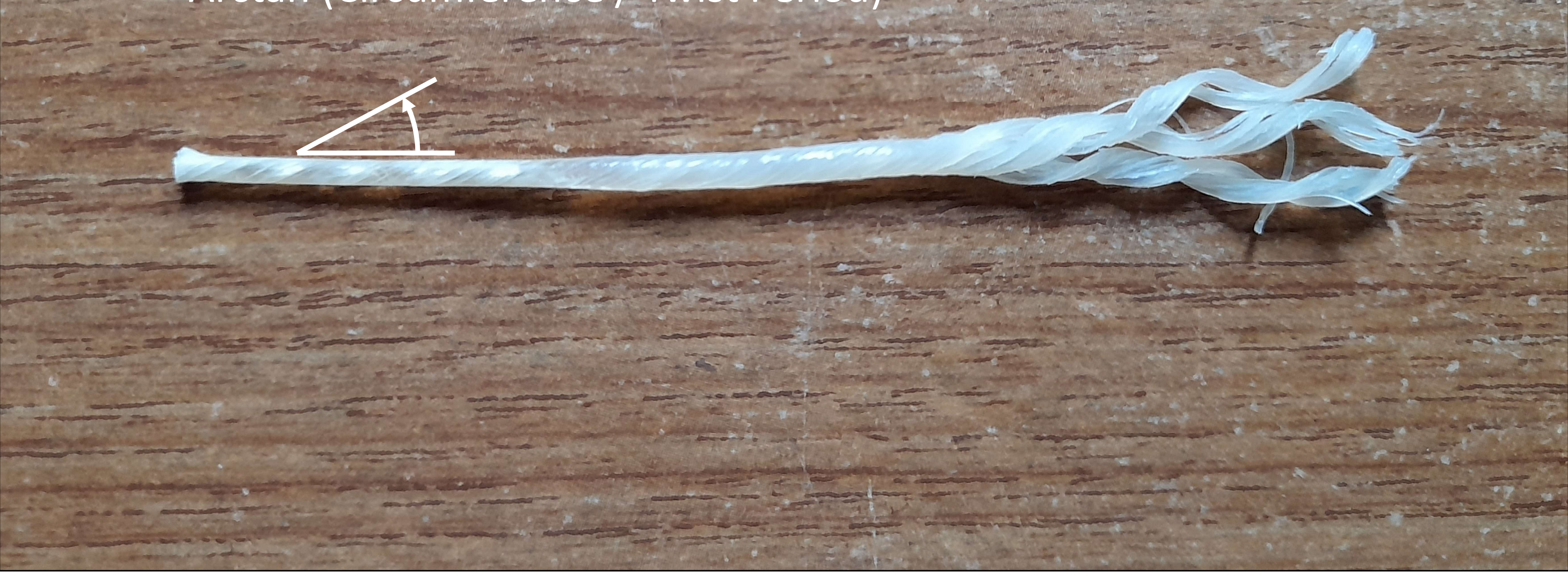




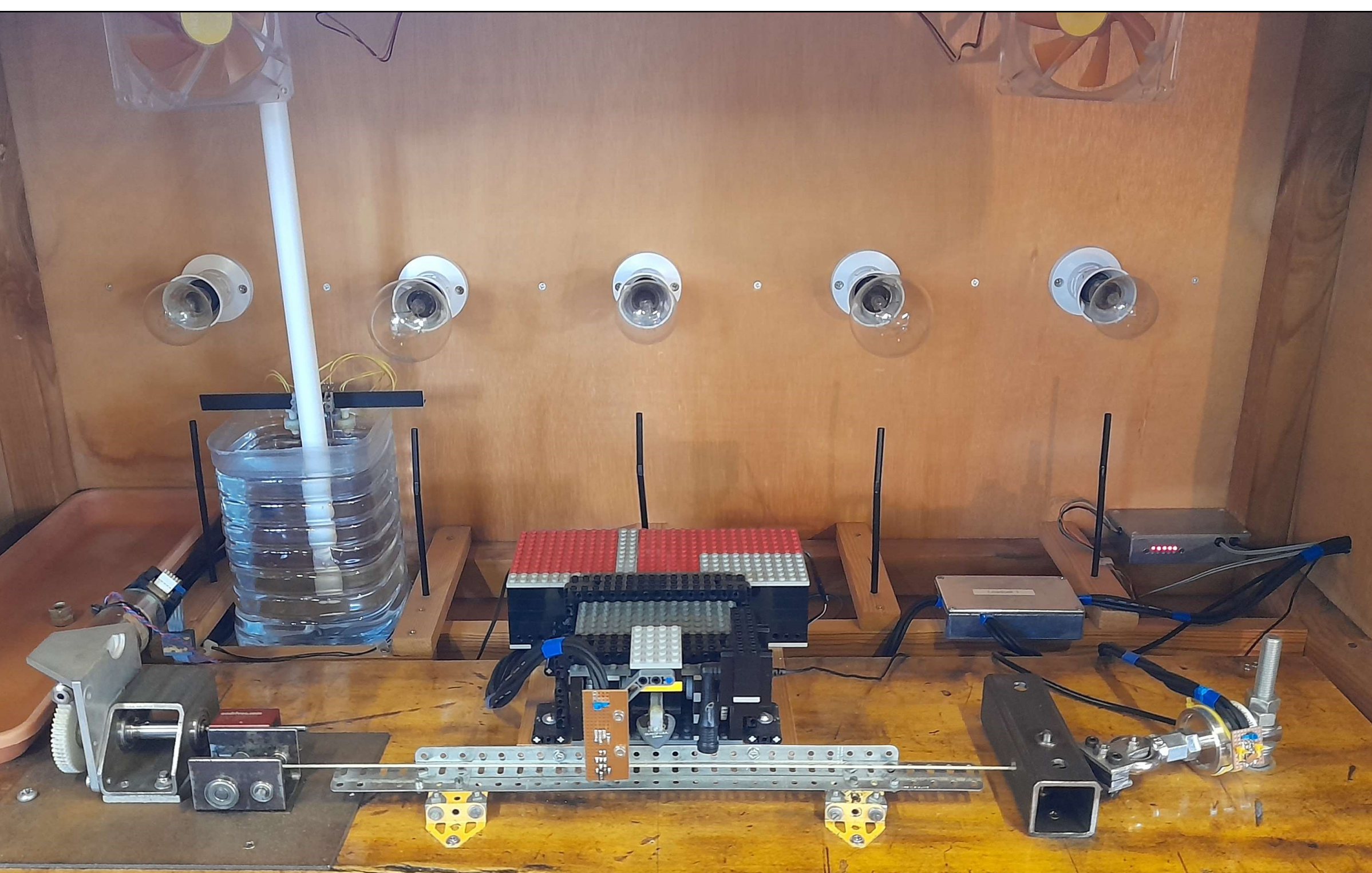




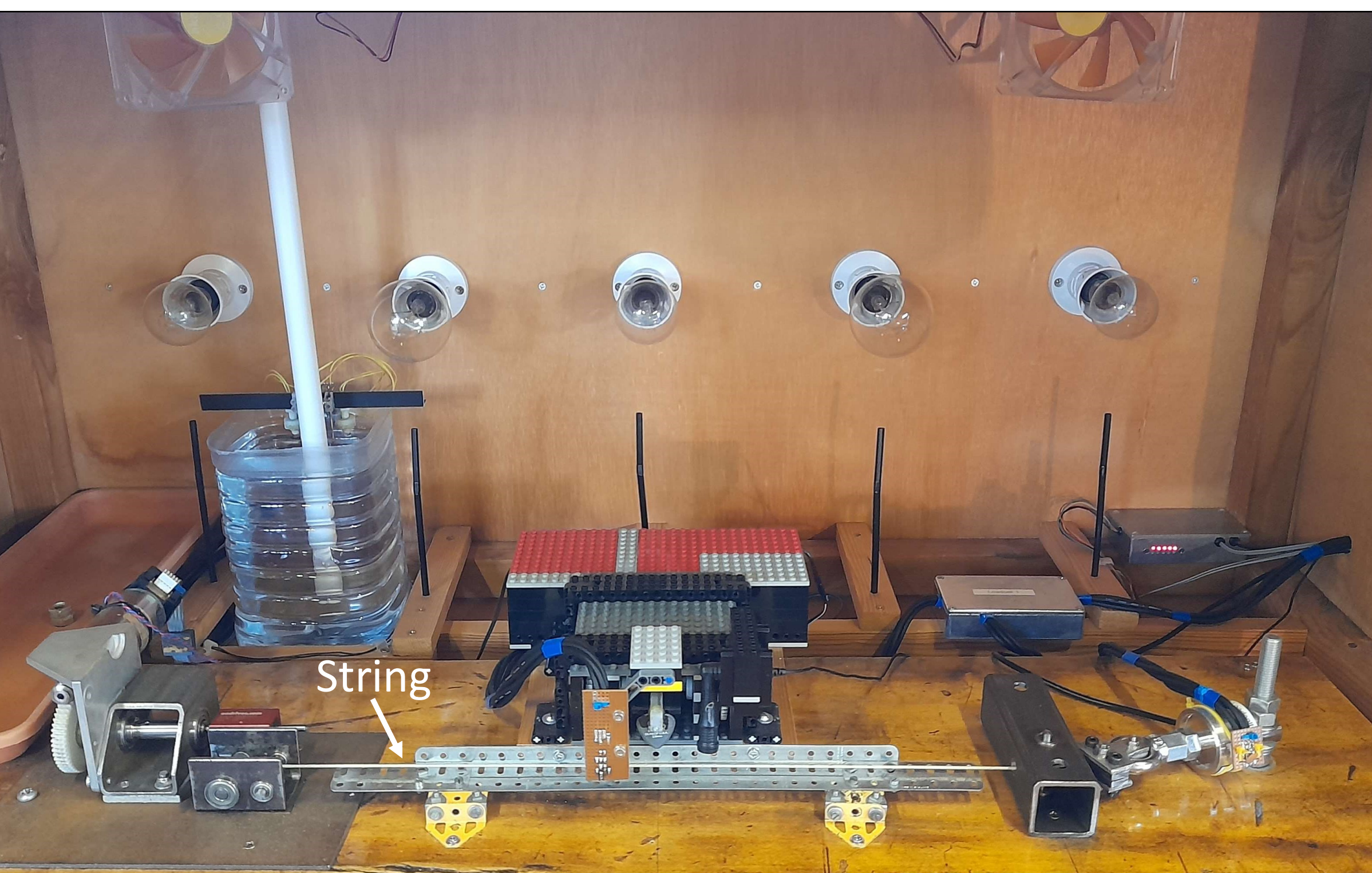




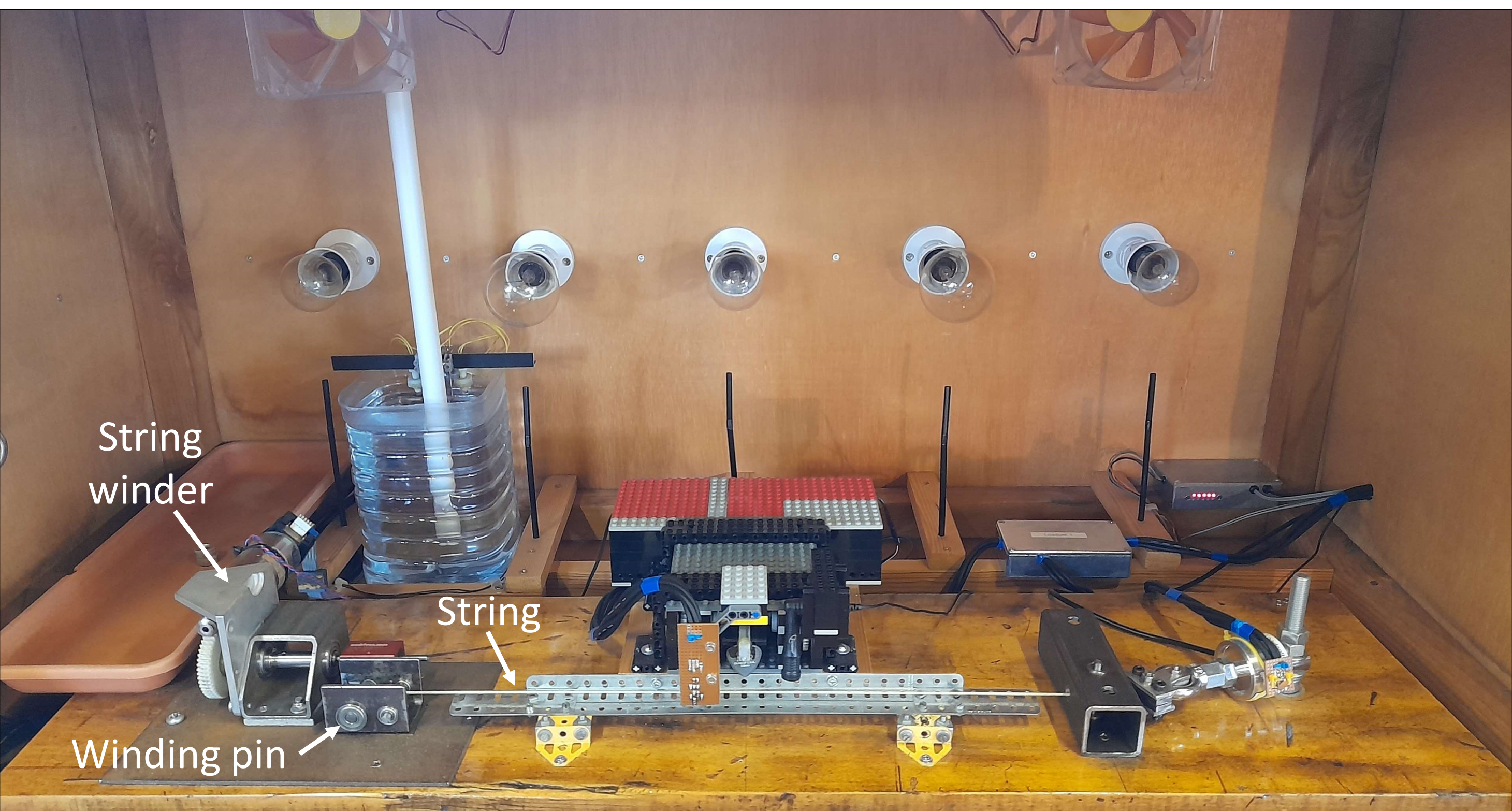

Winding pin 


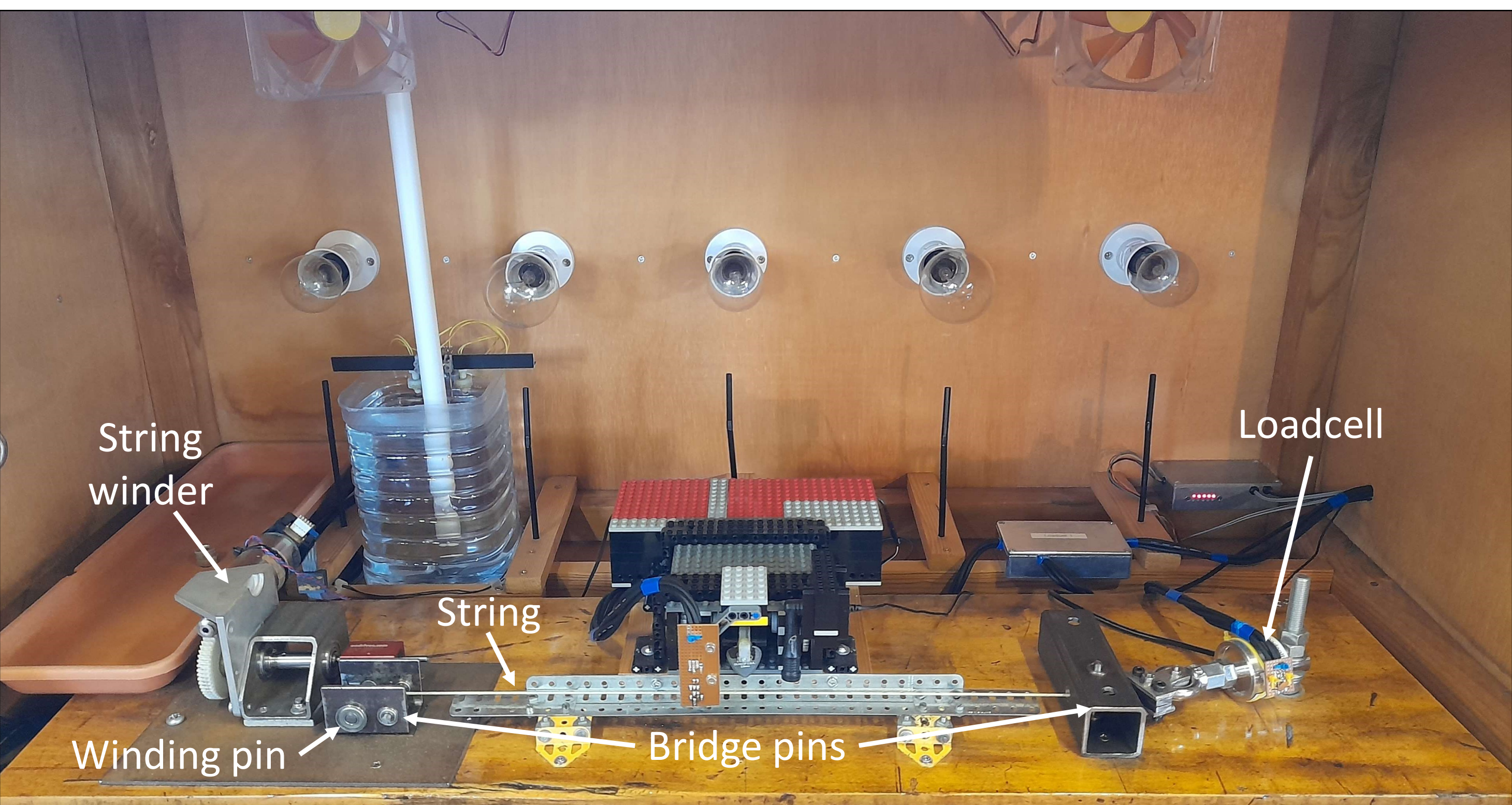

Winding pin 


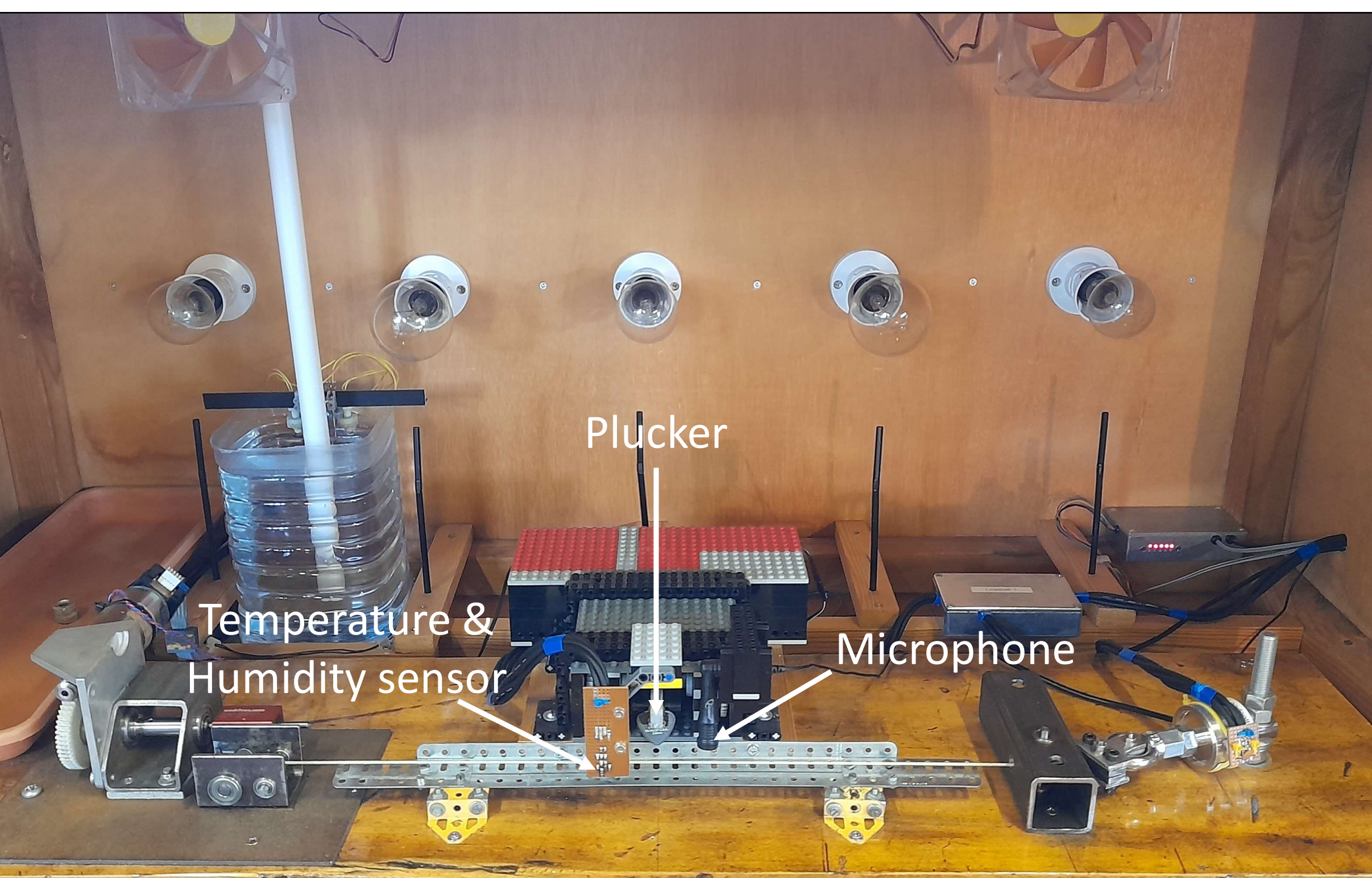




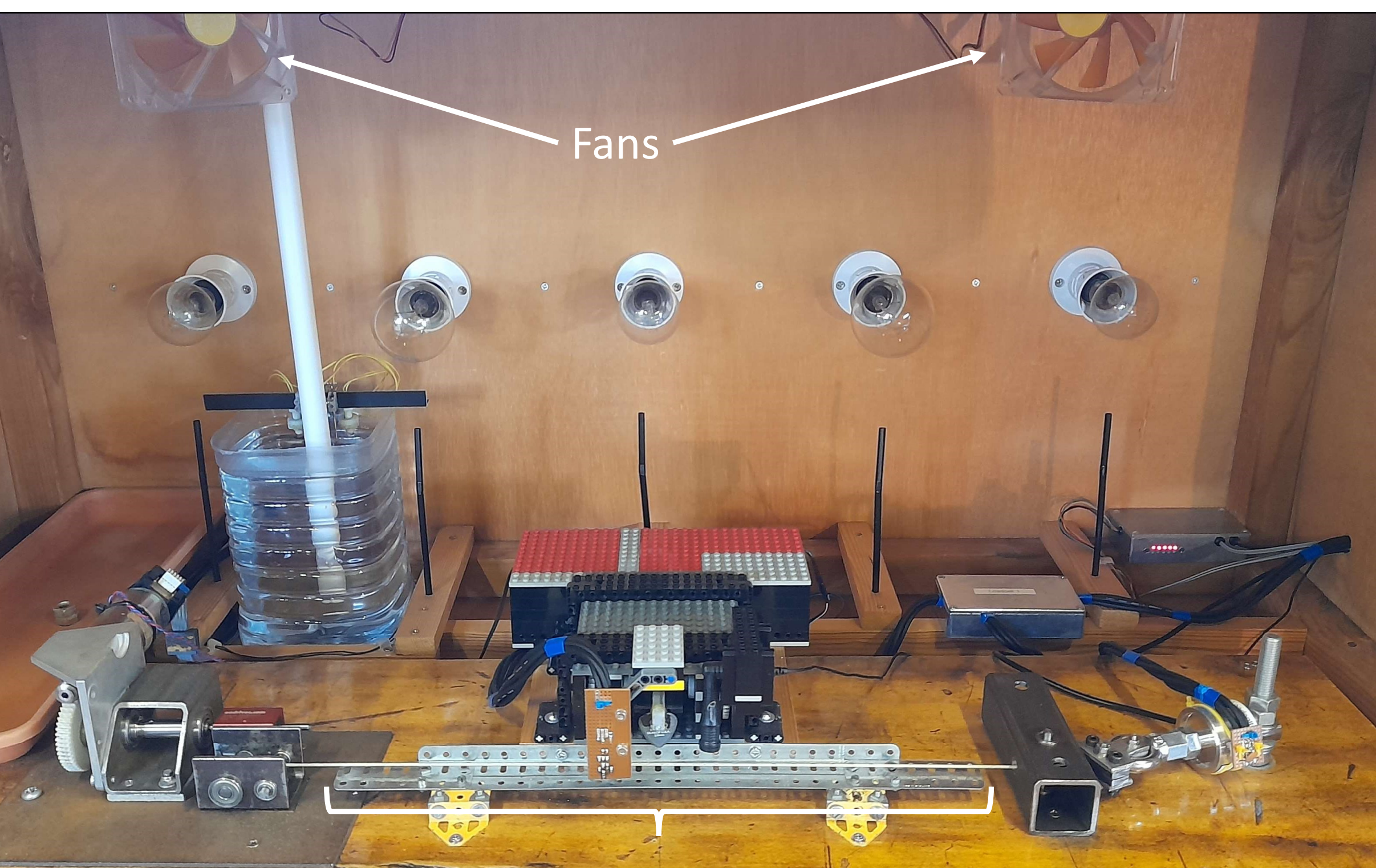




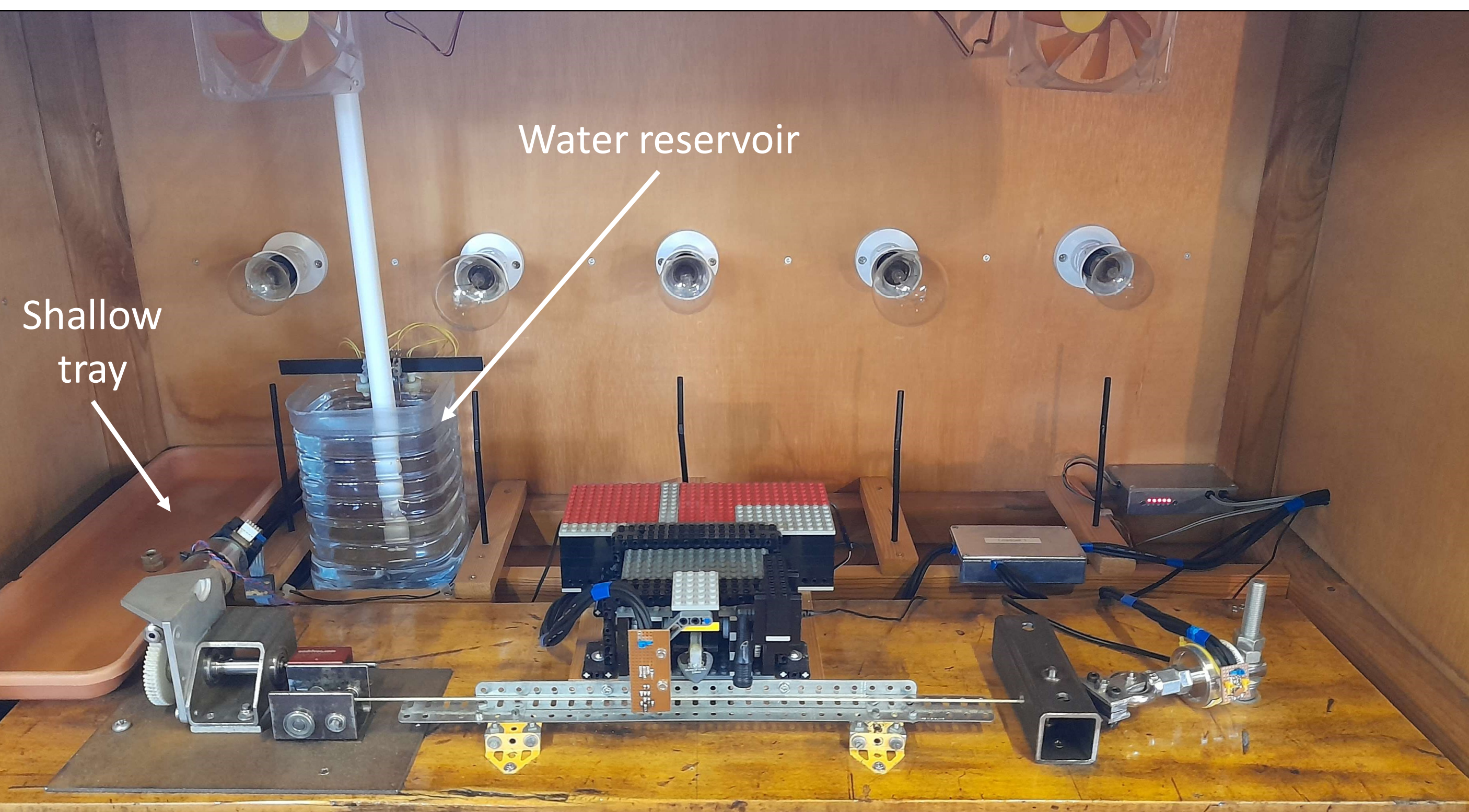

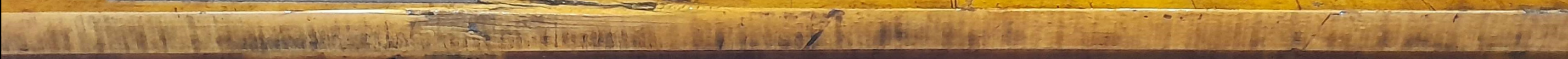



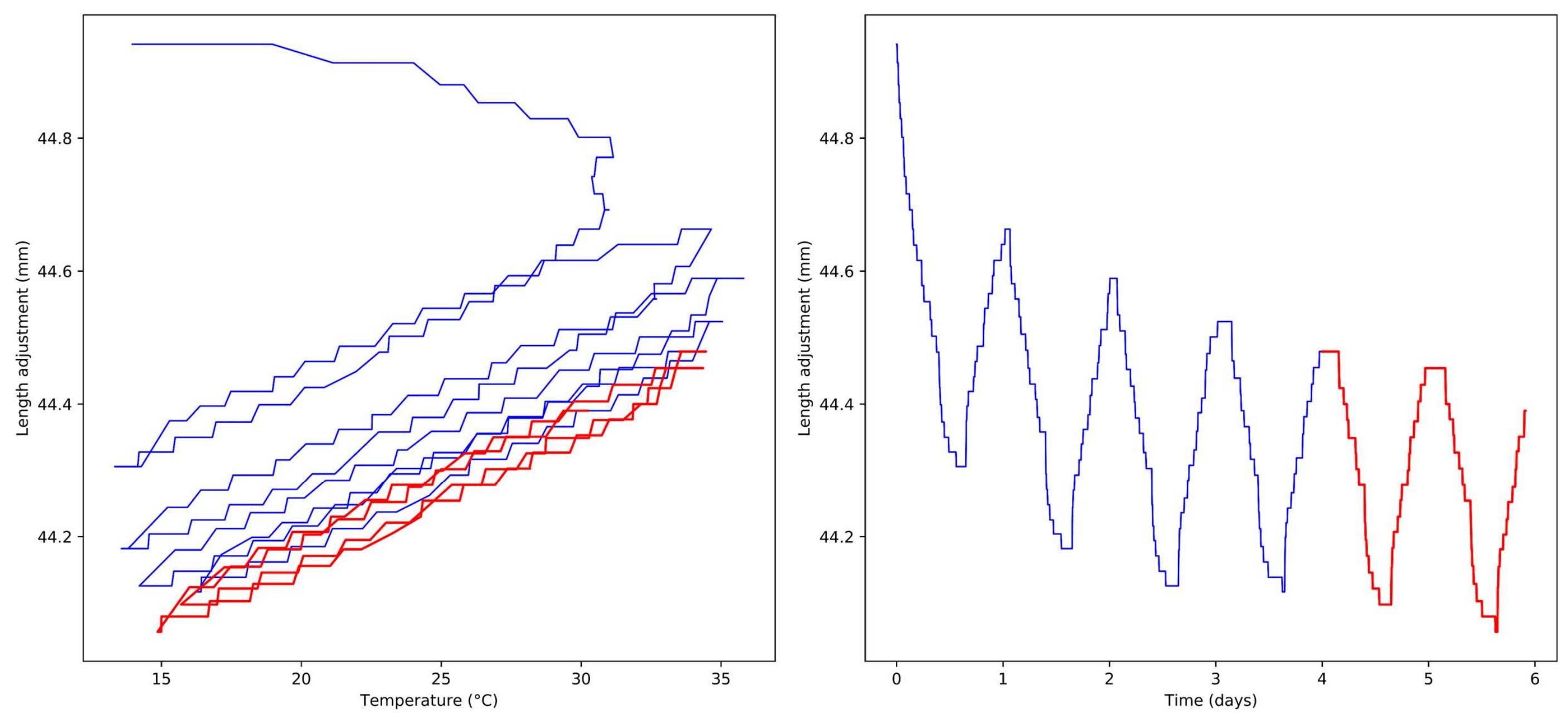

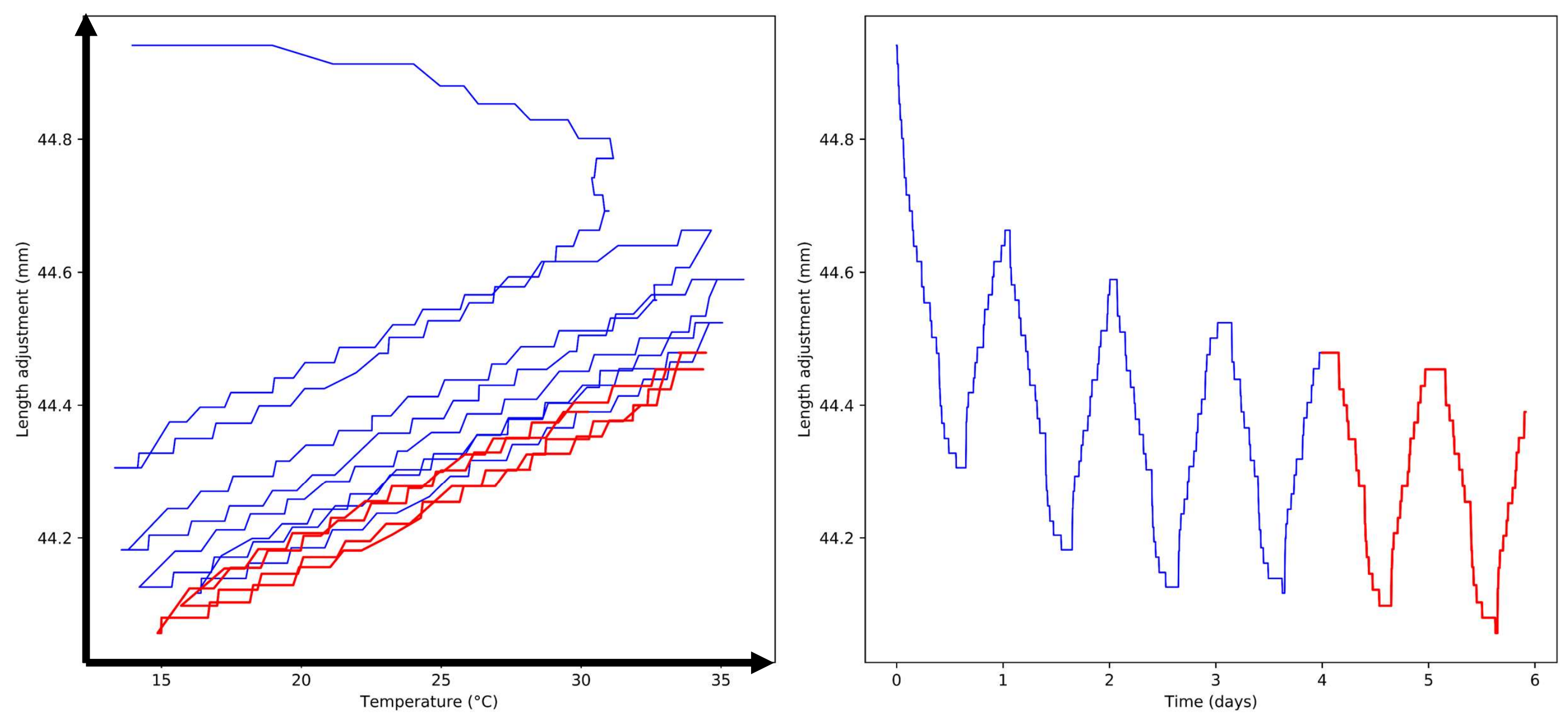

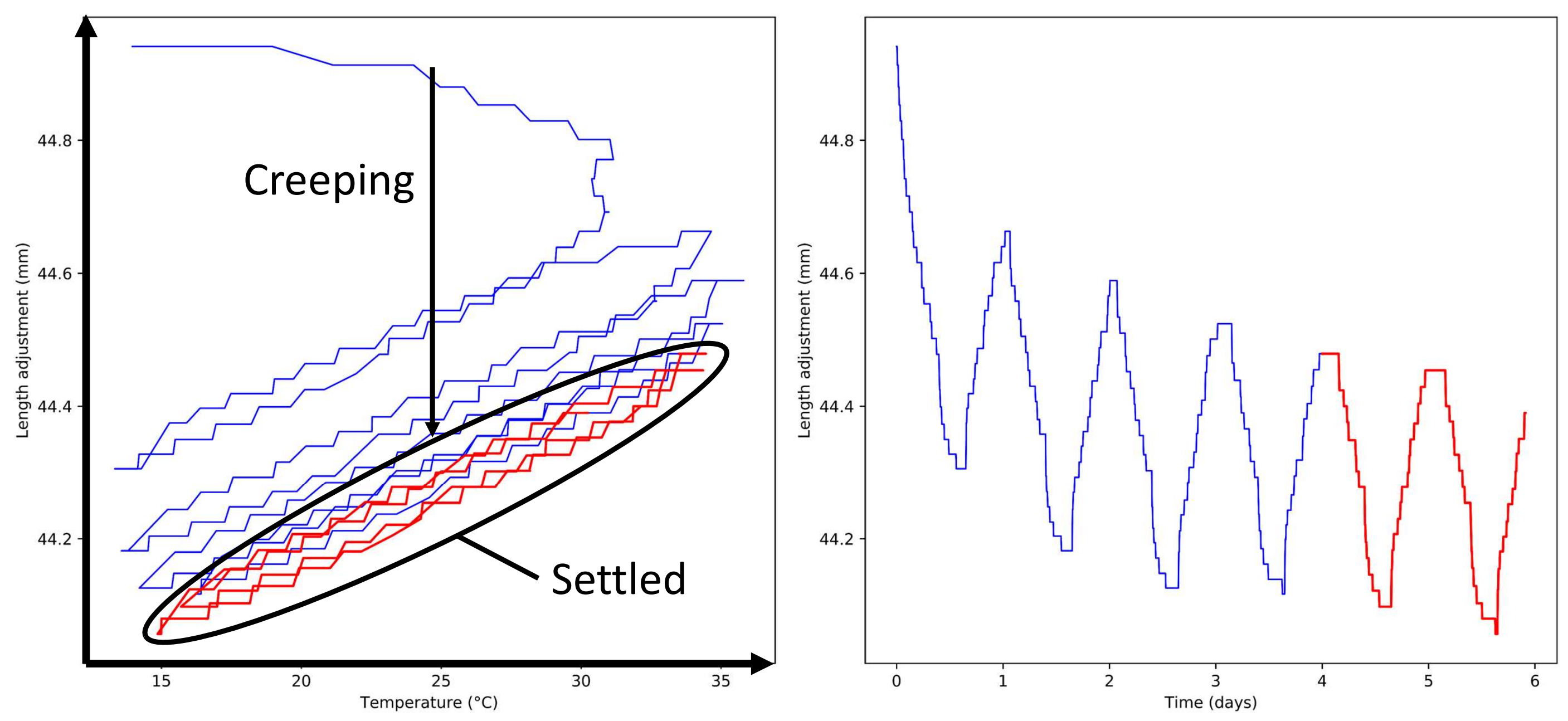

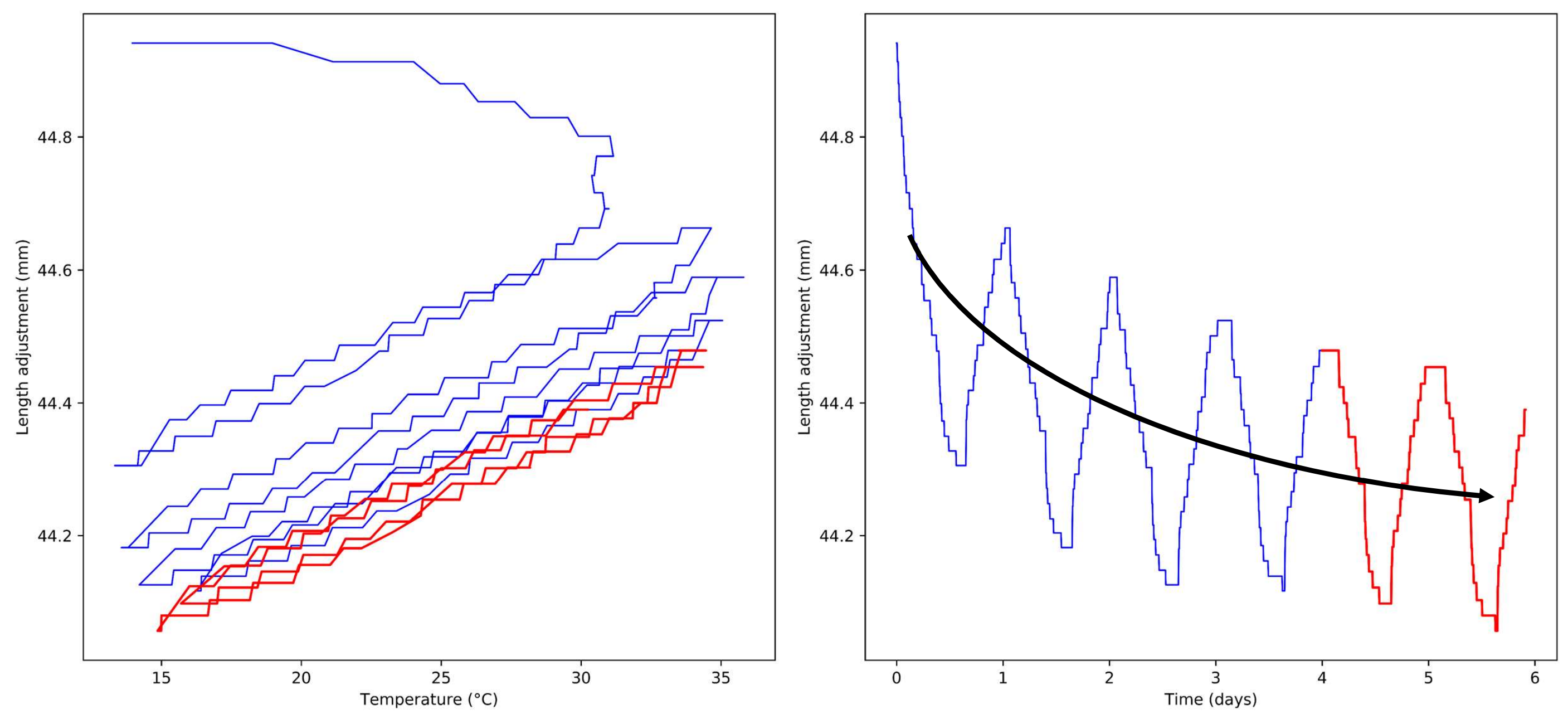
T3Aa at $324 \mathrm{~Hz}$ (Rig 1)

Twist angle $=24^{\circ}$
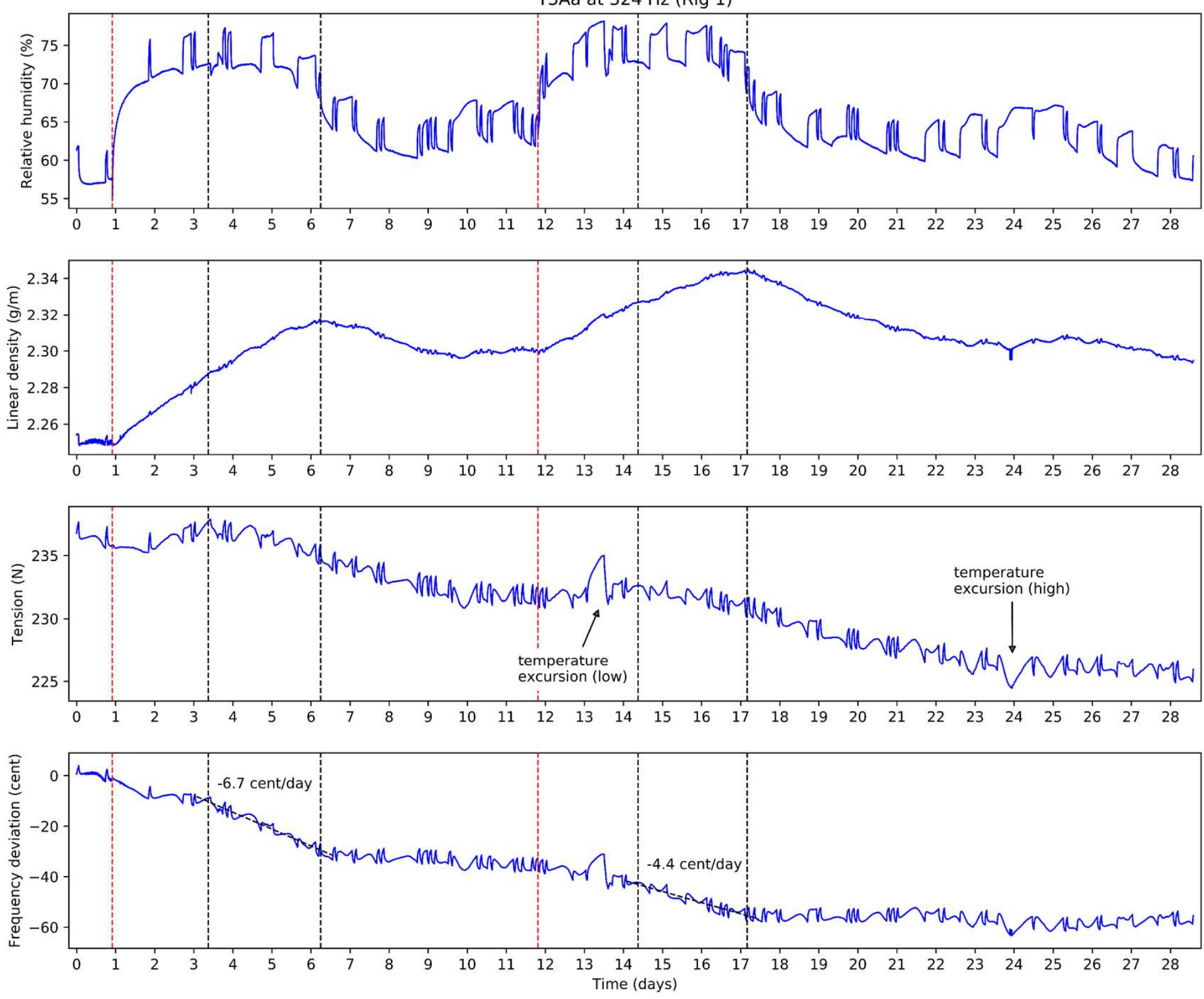


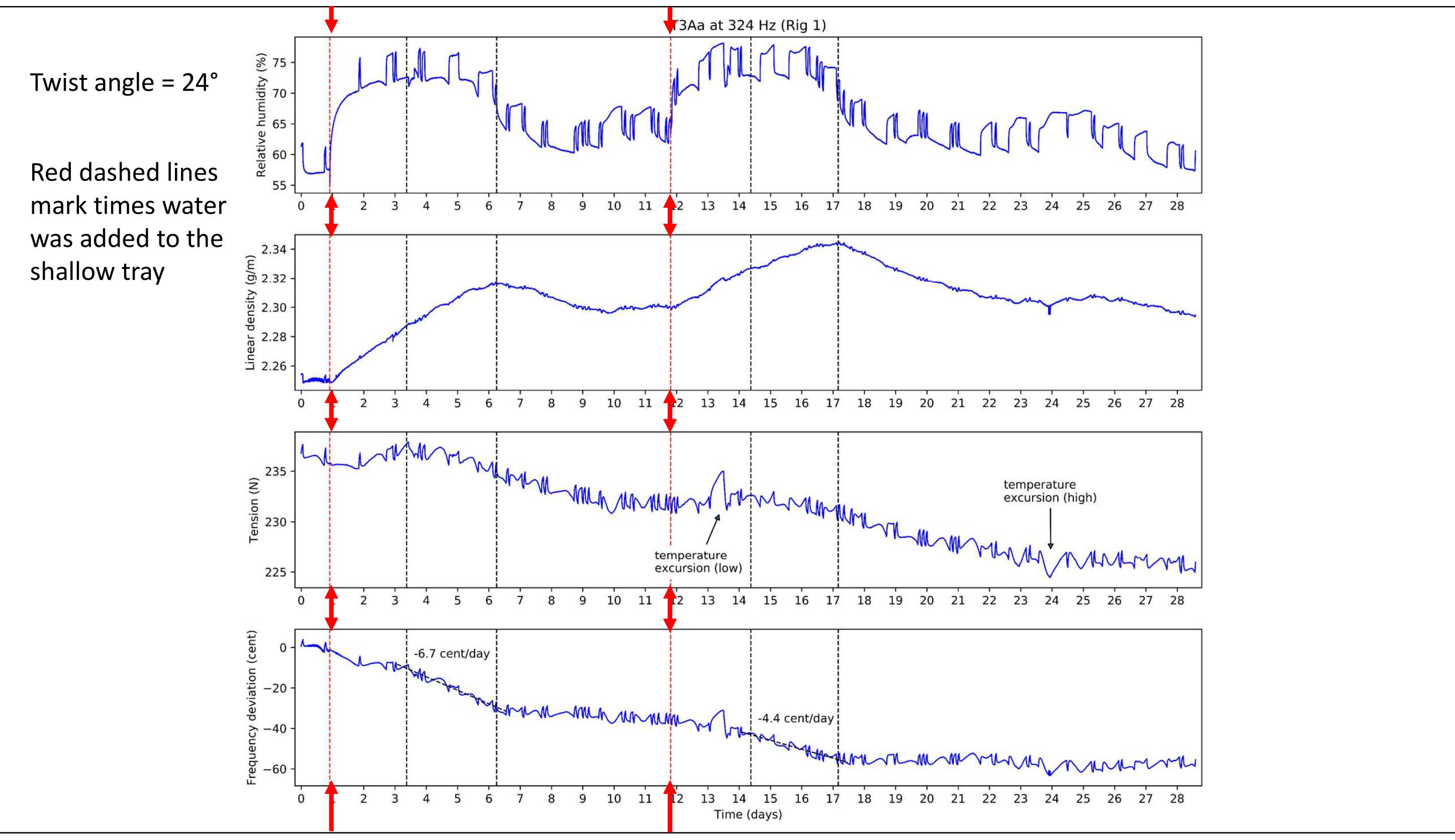


T3Aa at $324 \mathrm{~Hz}$ (Rig 1)

Twist angle $=24^{\circ}$
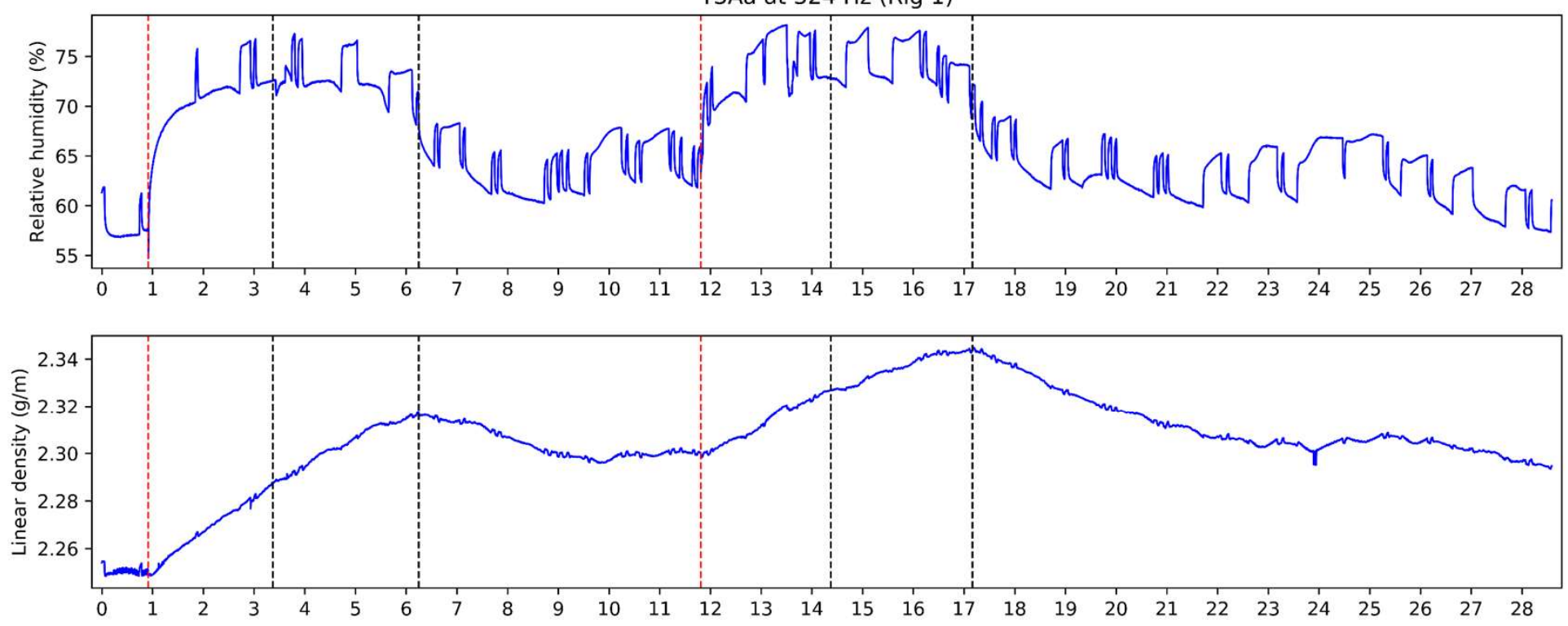

\section{Transition points in string tension correspond to start of apparent creep}
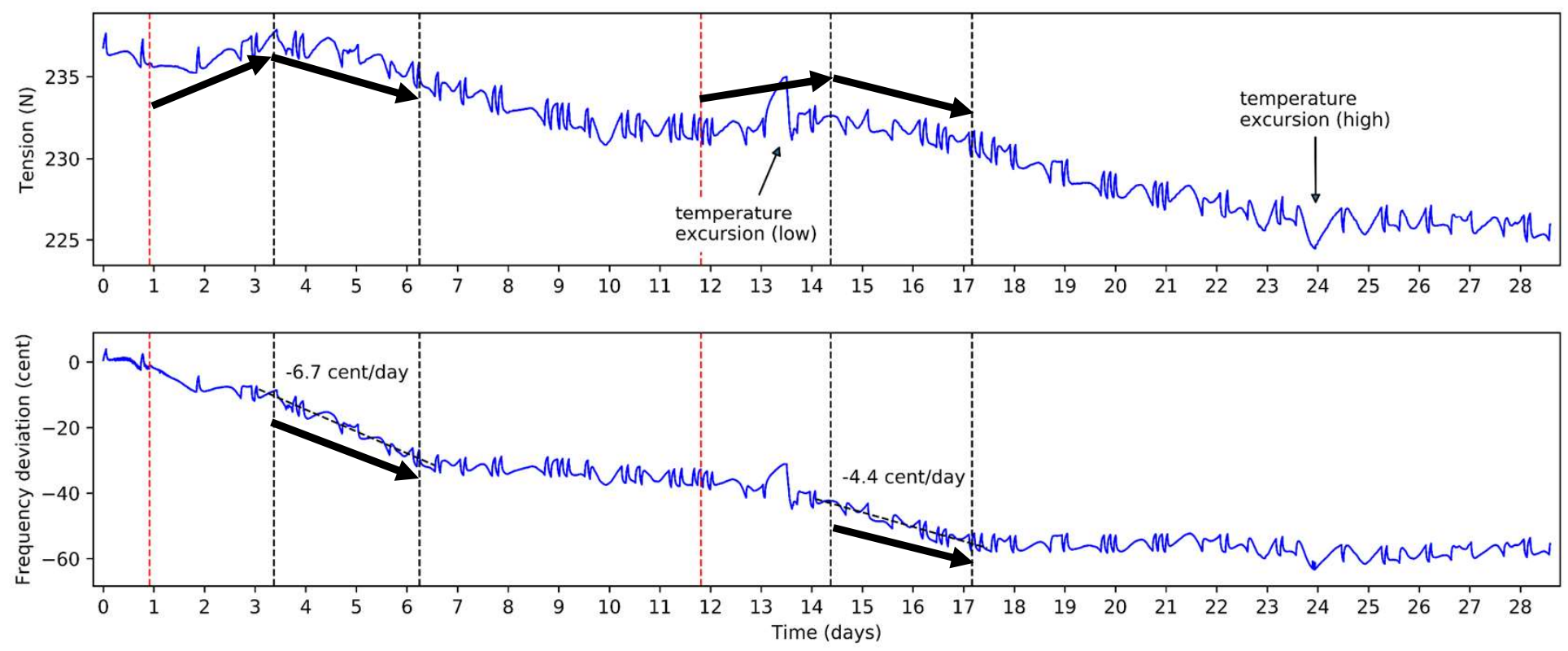
T3Aa at $324 \mathrm{~Hz}$ (Rig 1)

Twist angle $=24^{\circ}$

Is there a

threshold

effect?
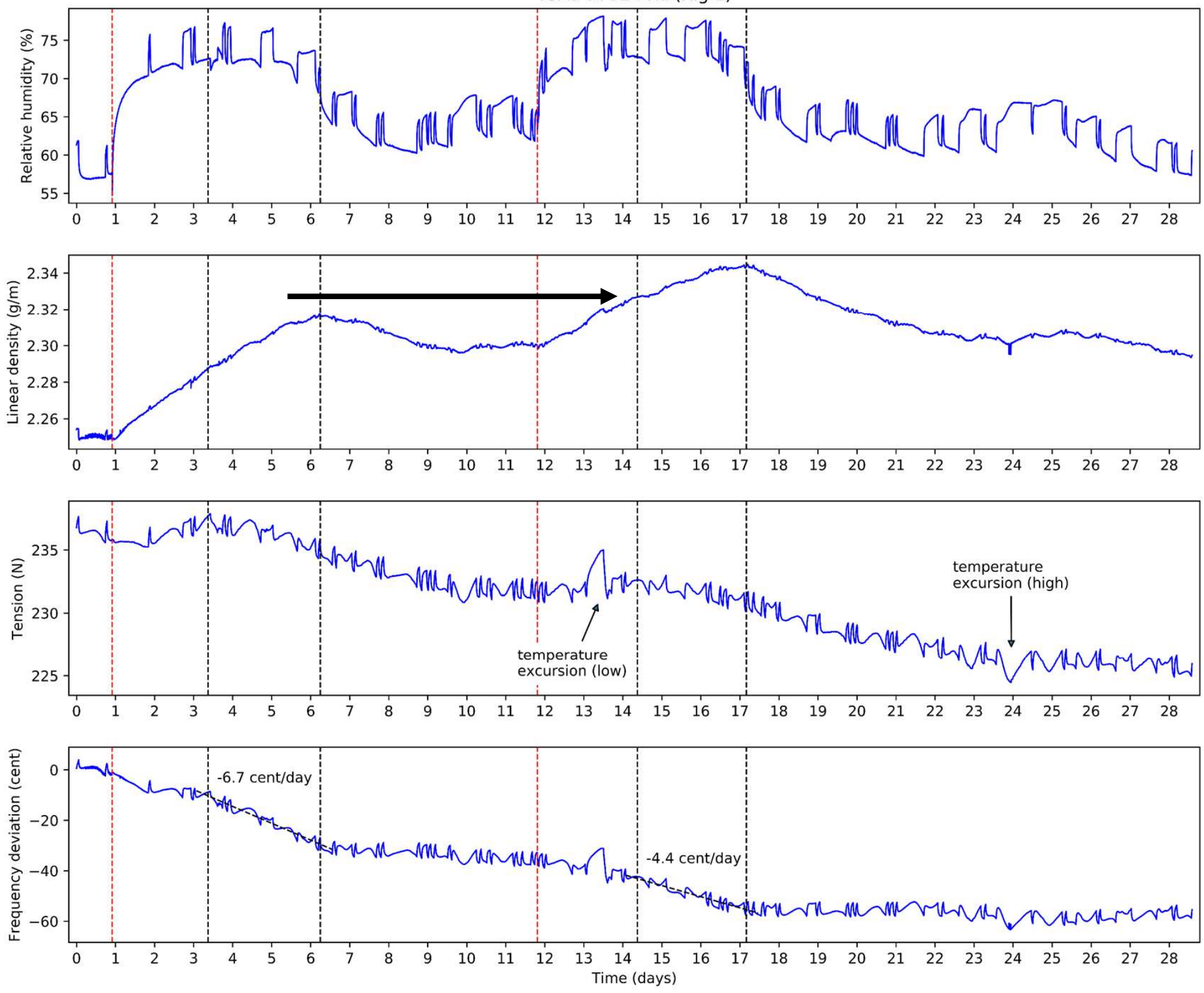
T3Aa at $324 \mathrm{~Hz}$ (Rig 1)

Twist angle $=24^{\circ}$
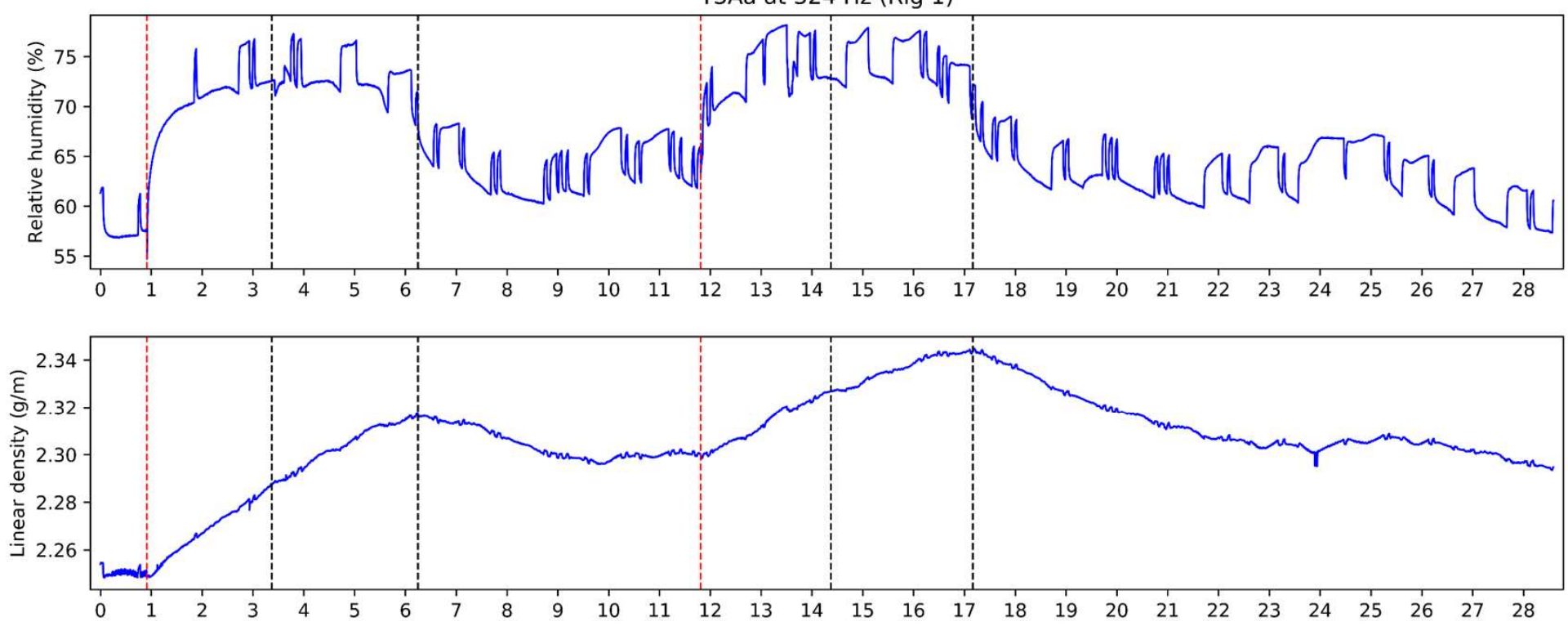

Changes in linear density \& tension

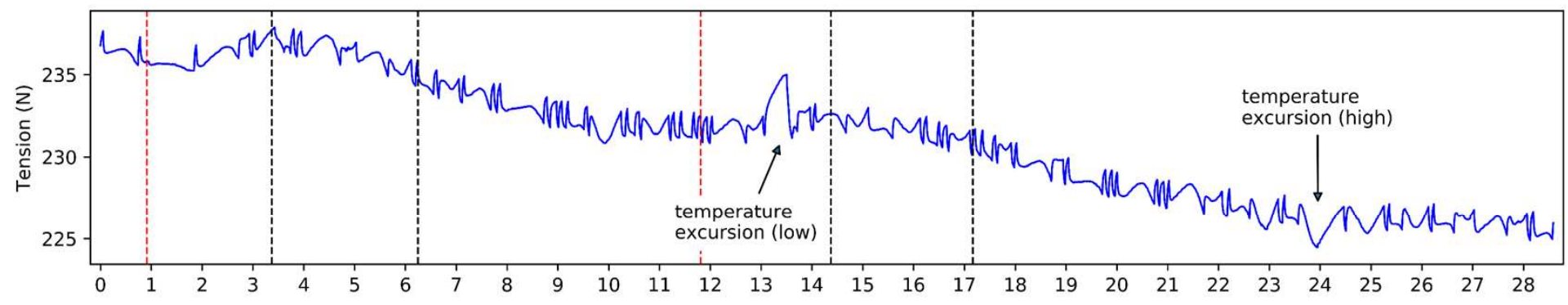
appeared to cancel with almost no net effect on the frequency (when not creeping)

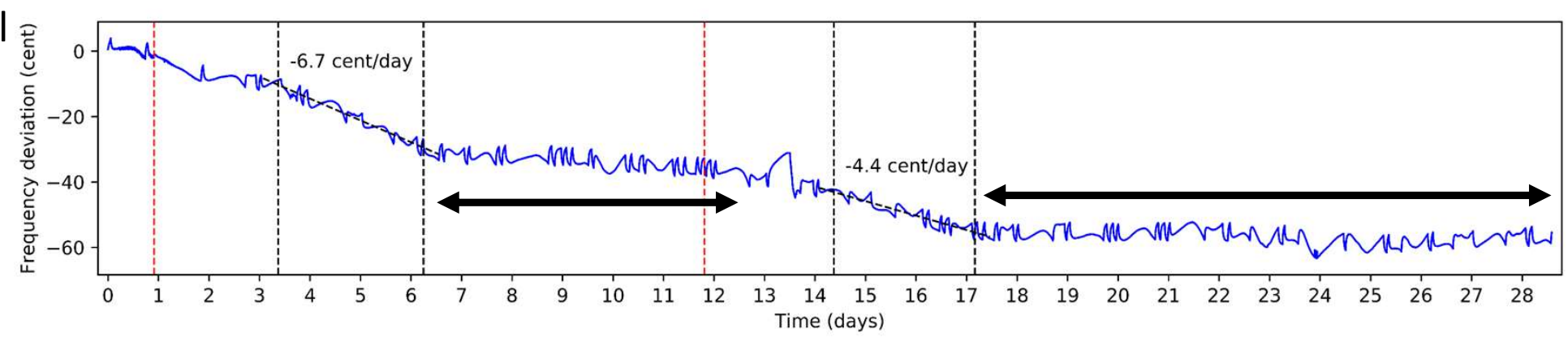


$\mathrm{T} 3 \mathrm{Bb}$ at $324 \mathrm{~Hz}$ (Rig 2)

Twist angle $=29^{\circ}$

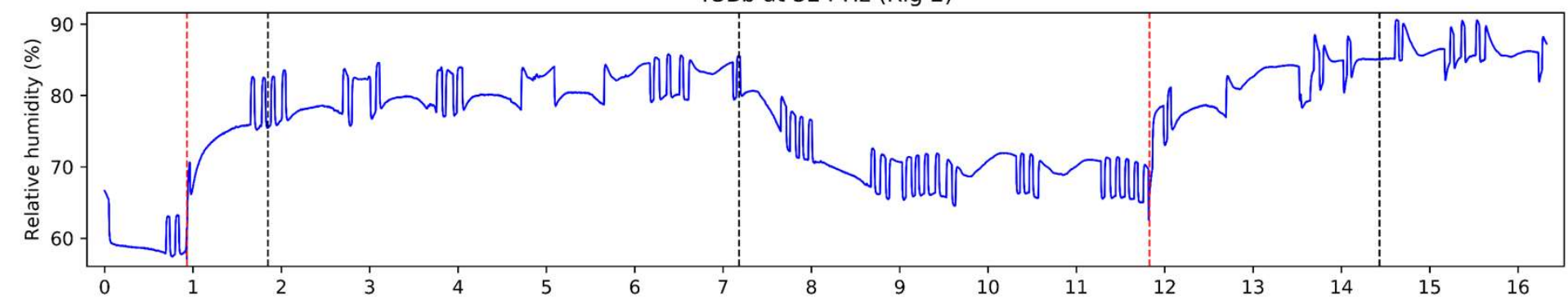

String taken from same initial bundle as previous one; only difference was the twist angle

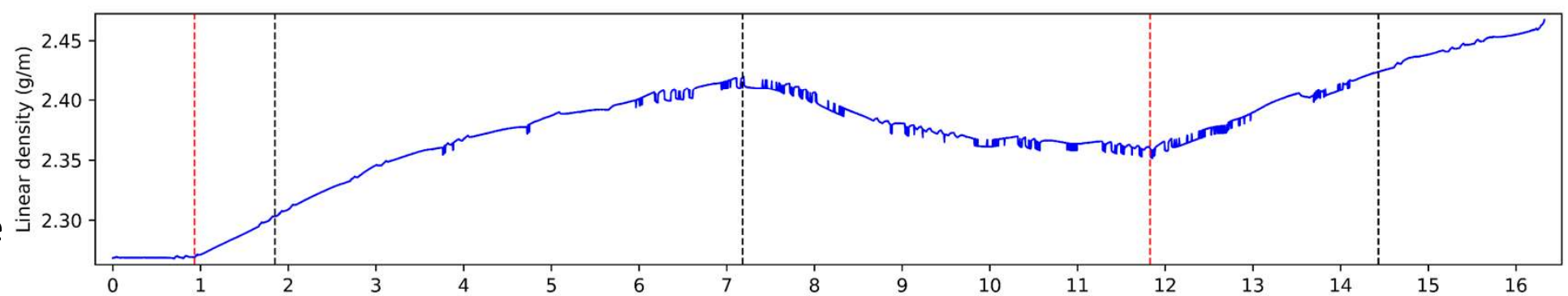

Showed the same behaviour - until it broke
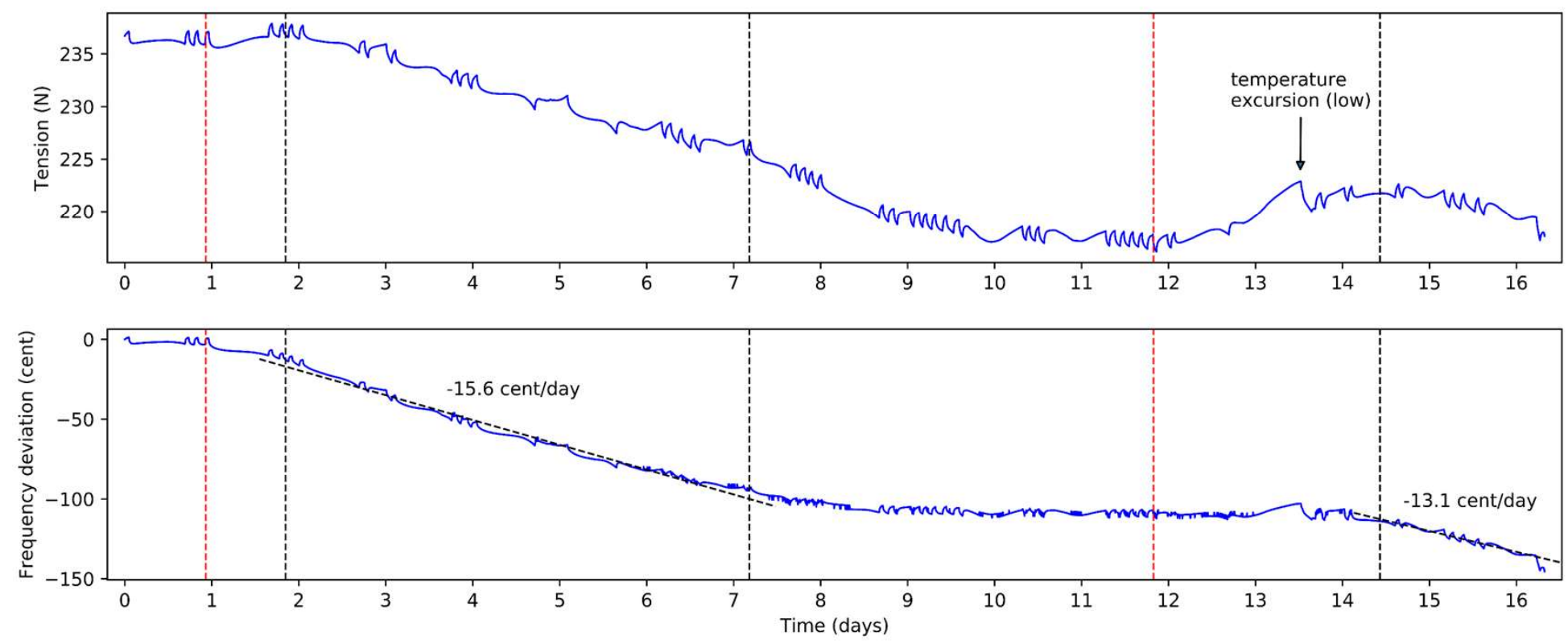
T3Bb at $324 \mathrm{~Hz}$ (Rig 2)

Twist angle $=29^{\circ}$
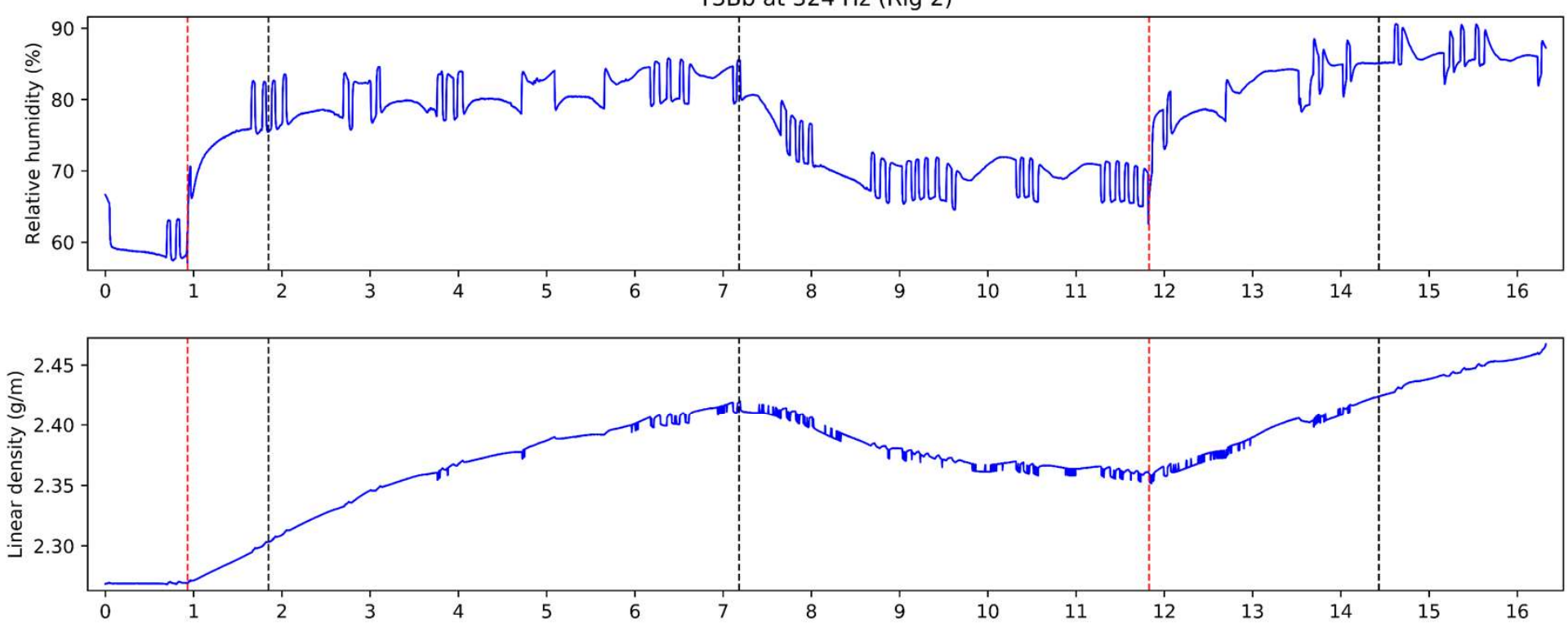

Transition points
in string tension
correspond to
start of apparent
creep

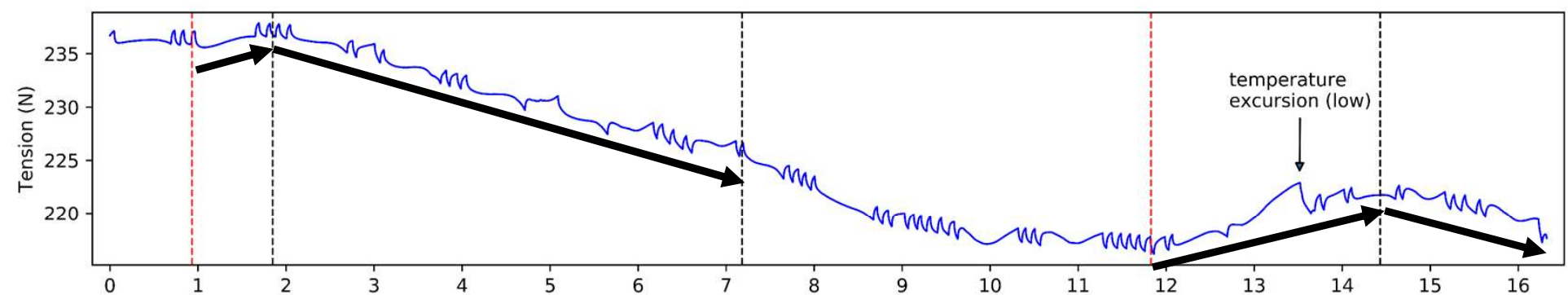

Creep rates more than twice those of previous string

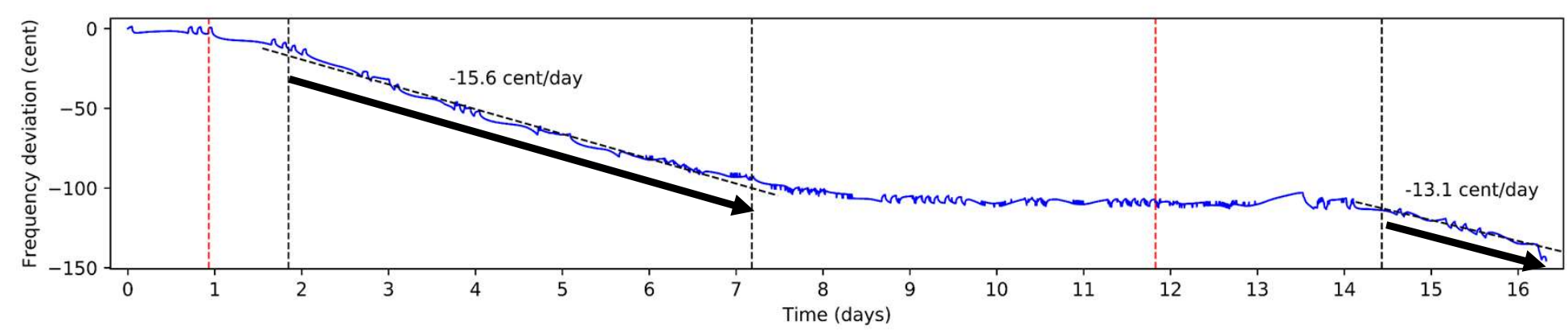


$\mathrm{T} 3 \mathrm{Bb}$ at $324 \mathrm{~Hz}$ (Rig 2)

Twist angle $=29^{\circ}$

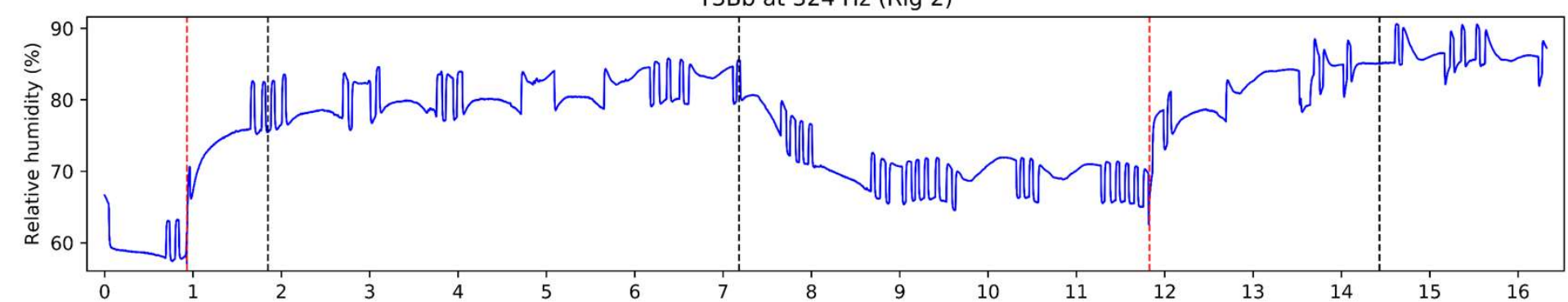

Same apparent threshold effect

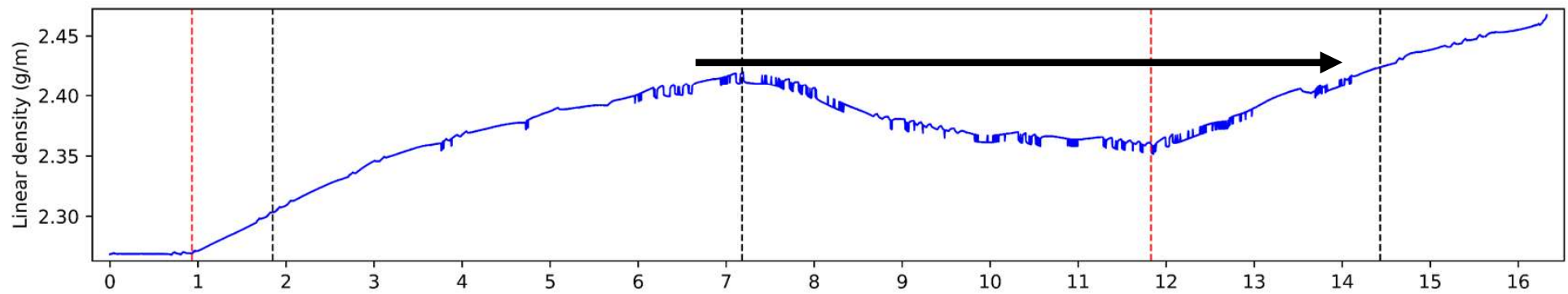

Changes in linear

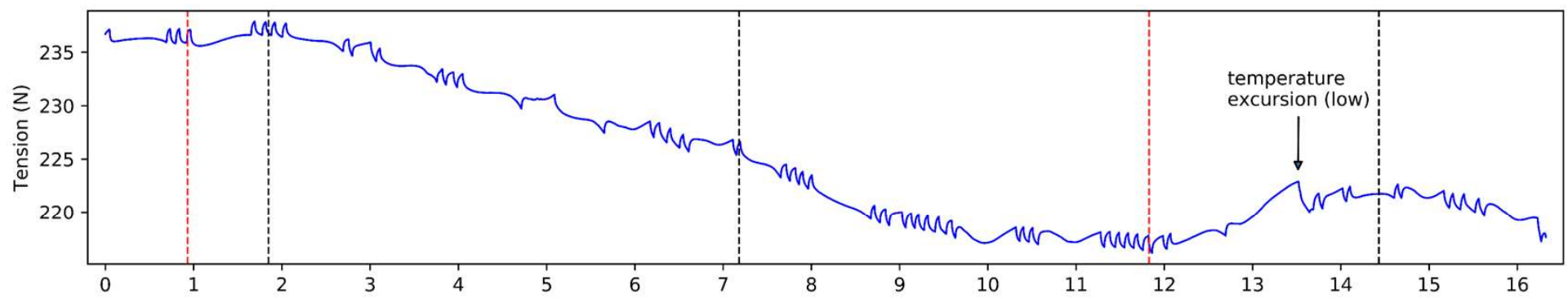
density \& tension again appeared to cancel with no net effect on the frequency

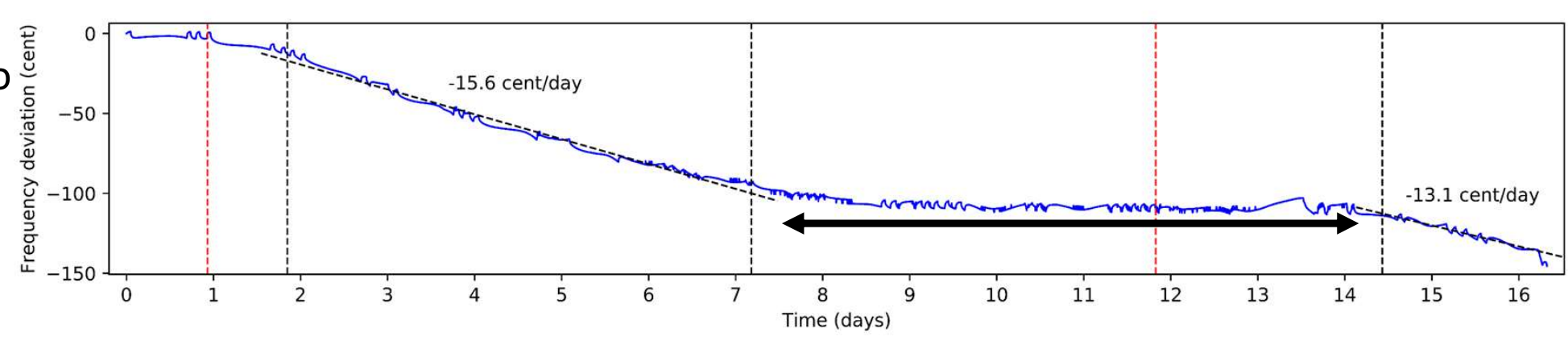


T3Bb at $324 \mathrm{~Hz}$ (Rig 2)

Twist angle $=29^{\circ}$
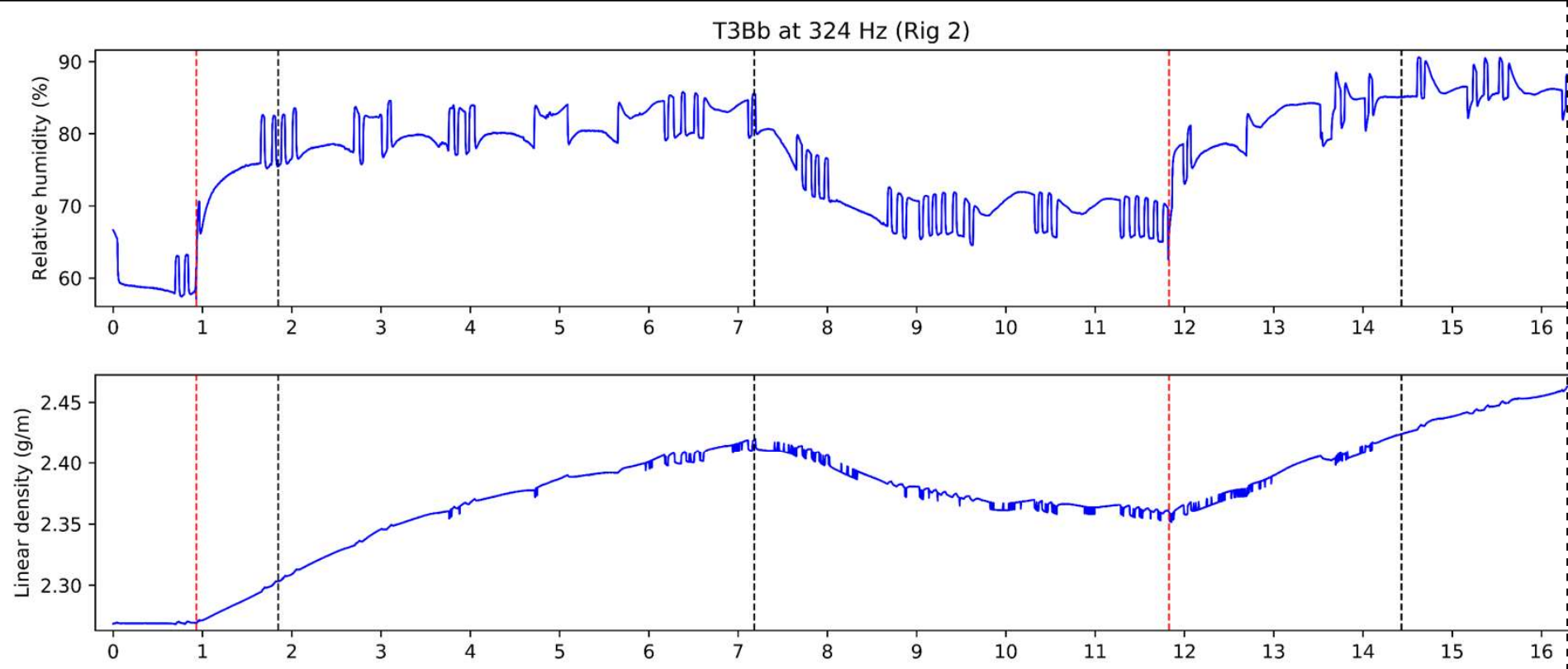

Just changing the humidity level caused this string to break

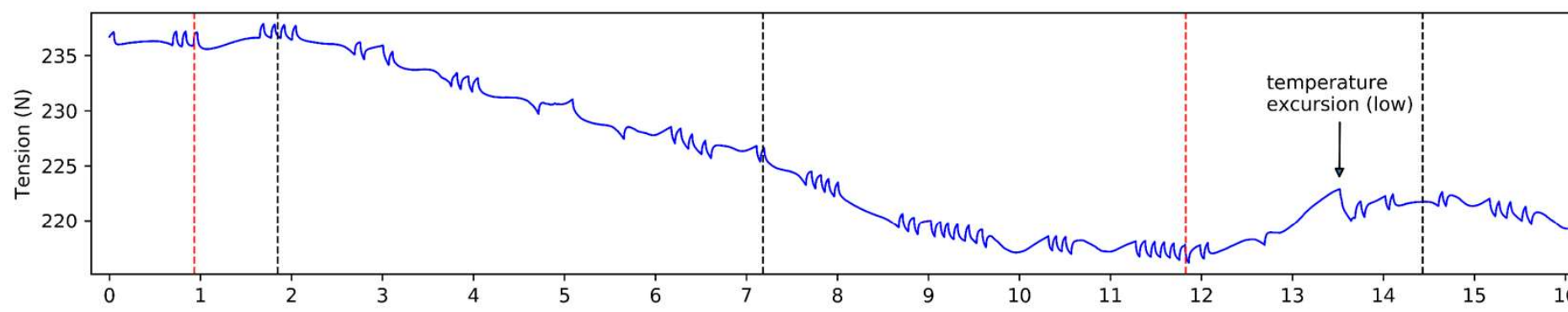

String broke at

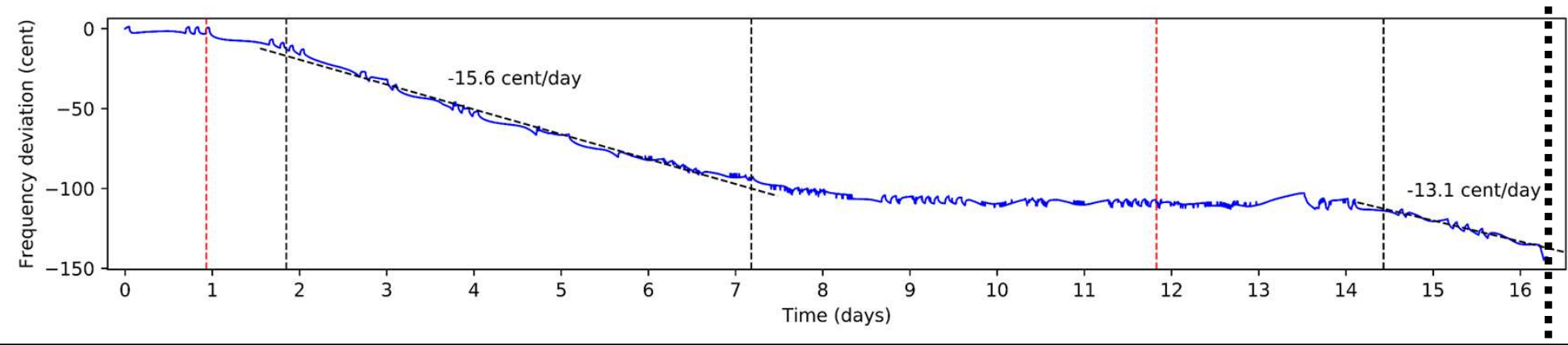
this time 
T1Aa at $324 \mathrm{~Hz}$ (Rig 1)

Twist angle $=36^{\circ}$
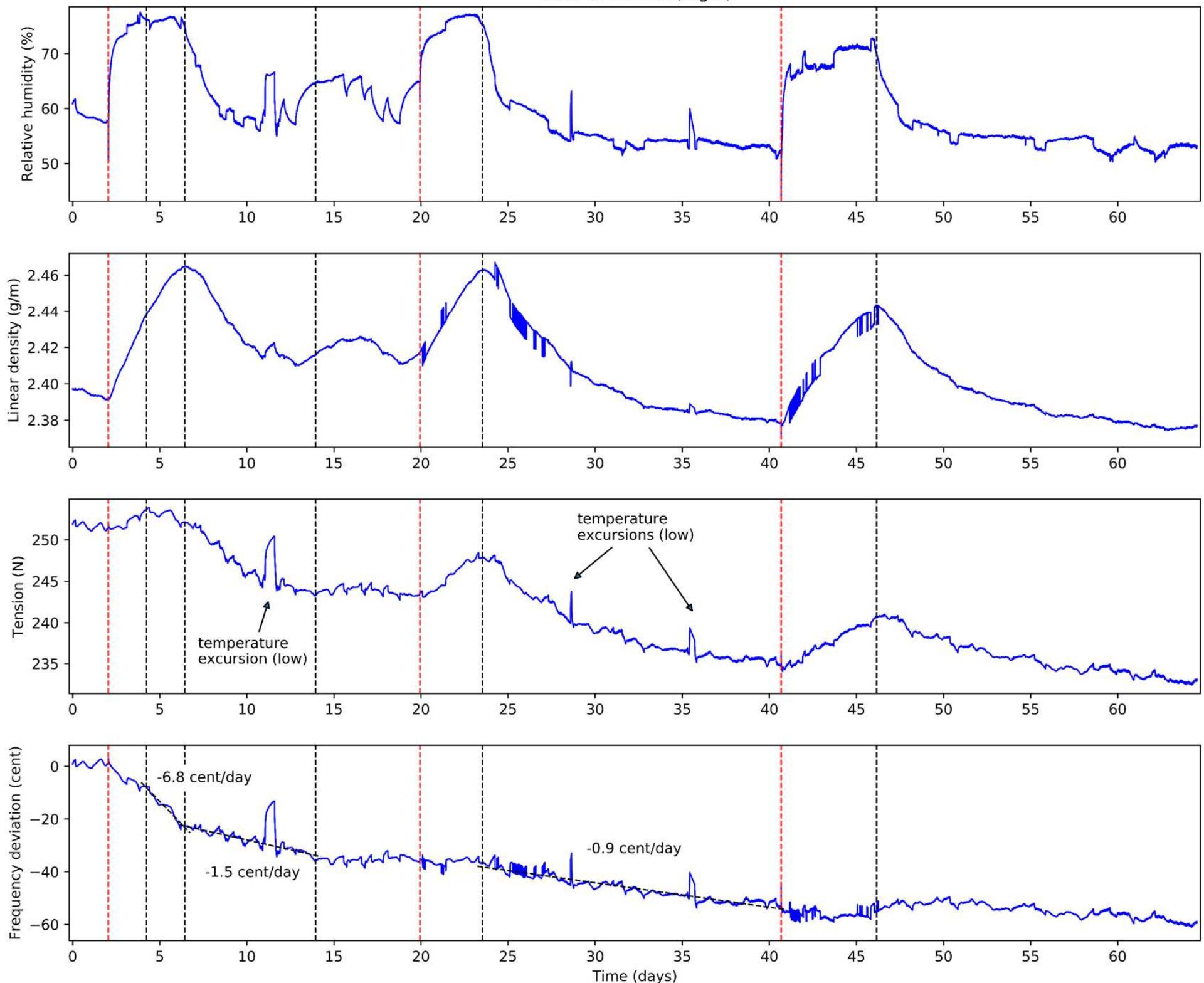
T1Aa at $324 \mathrm{~Hz}$ (Rig 1)

Twist angle $=36^{\circ}$
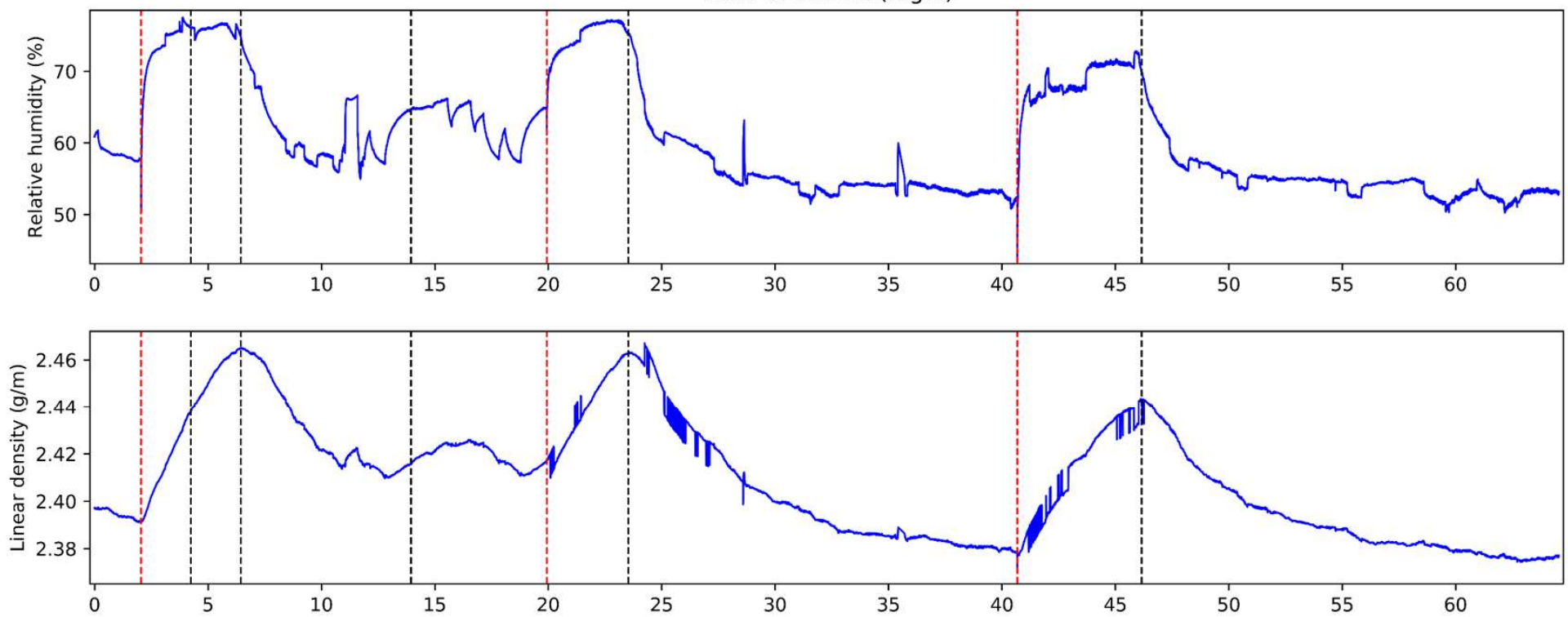

Initial behaviour similar to before

Similar creep rate to first string with twist angle of $24^{\circ}$
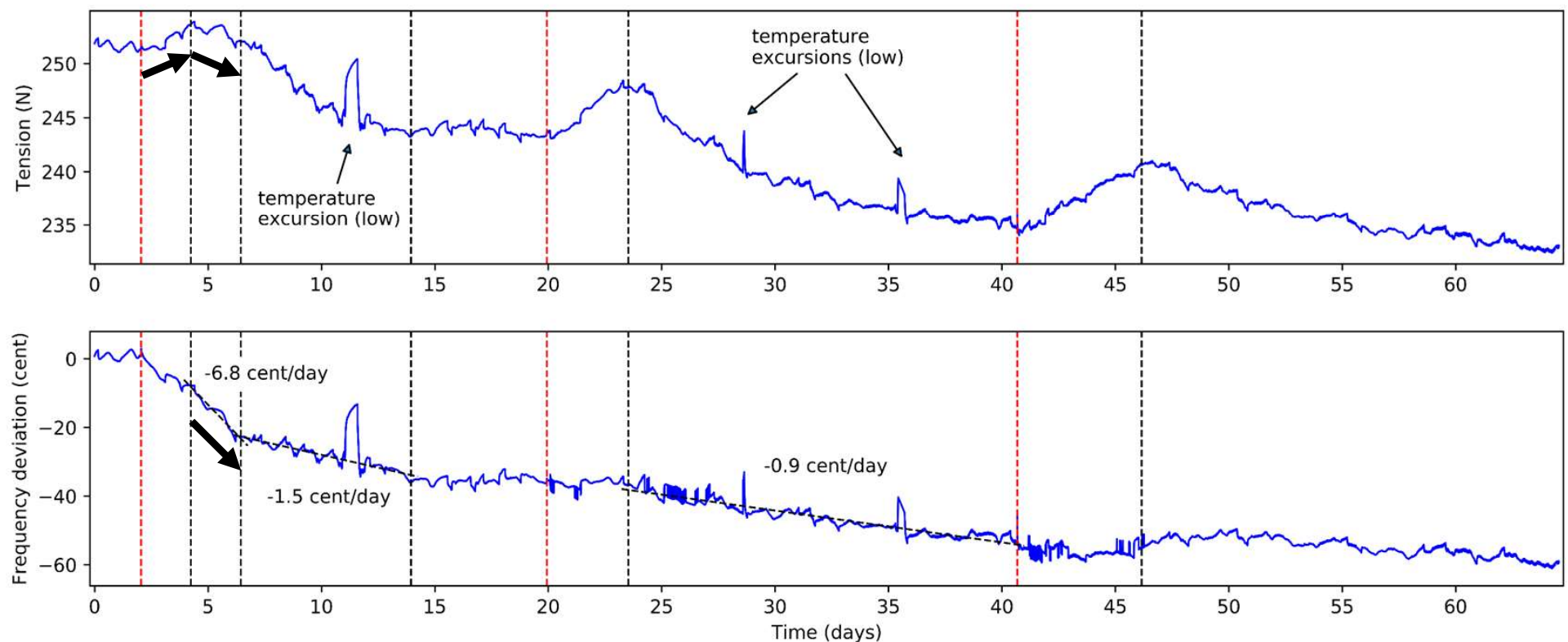
T1Aa at $324 \mathrm{~Hz}$ (Rig 1)

Twist angle $=36^{\circ}$

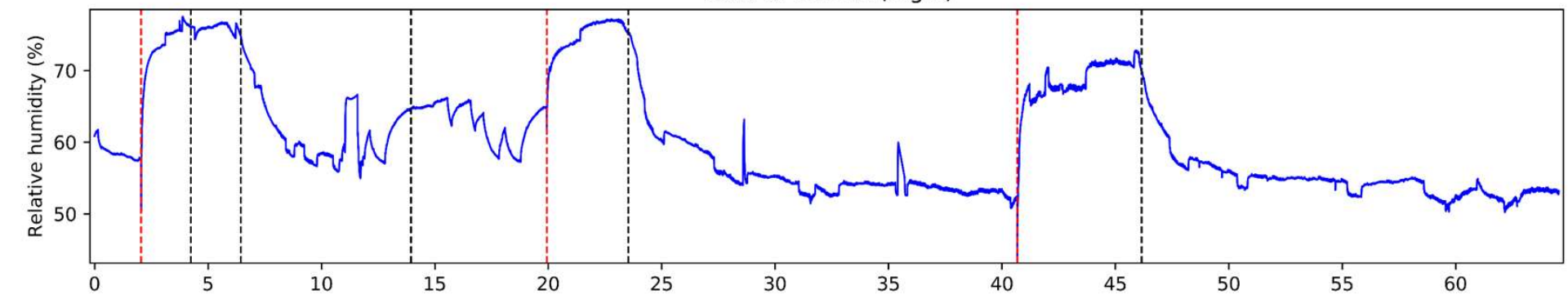

Linear density did not exceed previous maximum ...
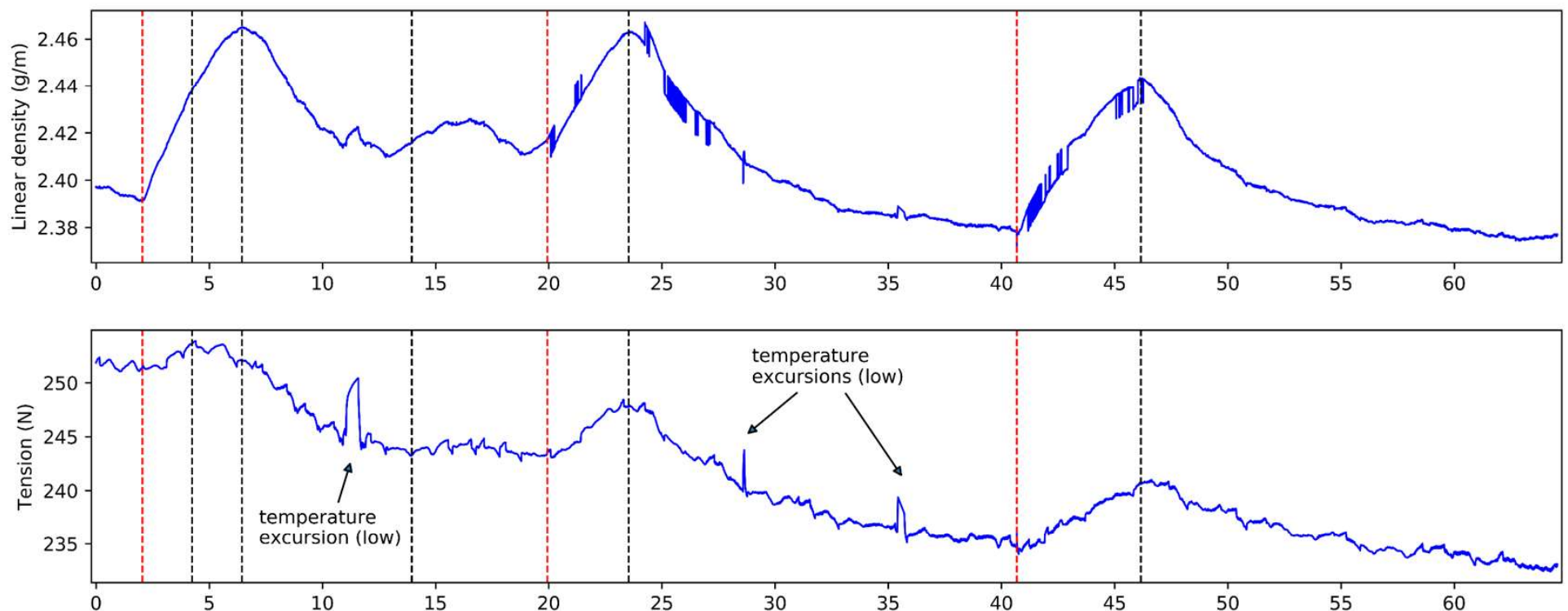

... but string twice appeared to creep at very slow rate following peaks in linear density

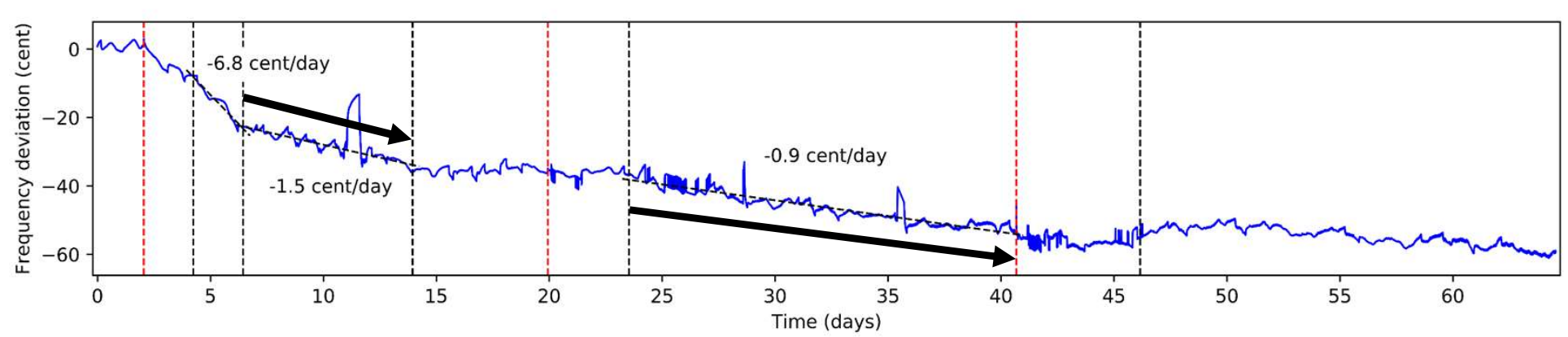


T1Aa at $324 \mathrm{~Hz}$ (Rig 1)

Twist angle $=36^{\circ}$
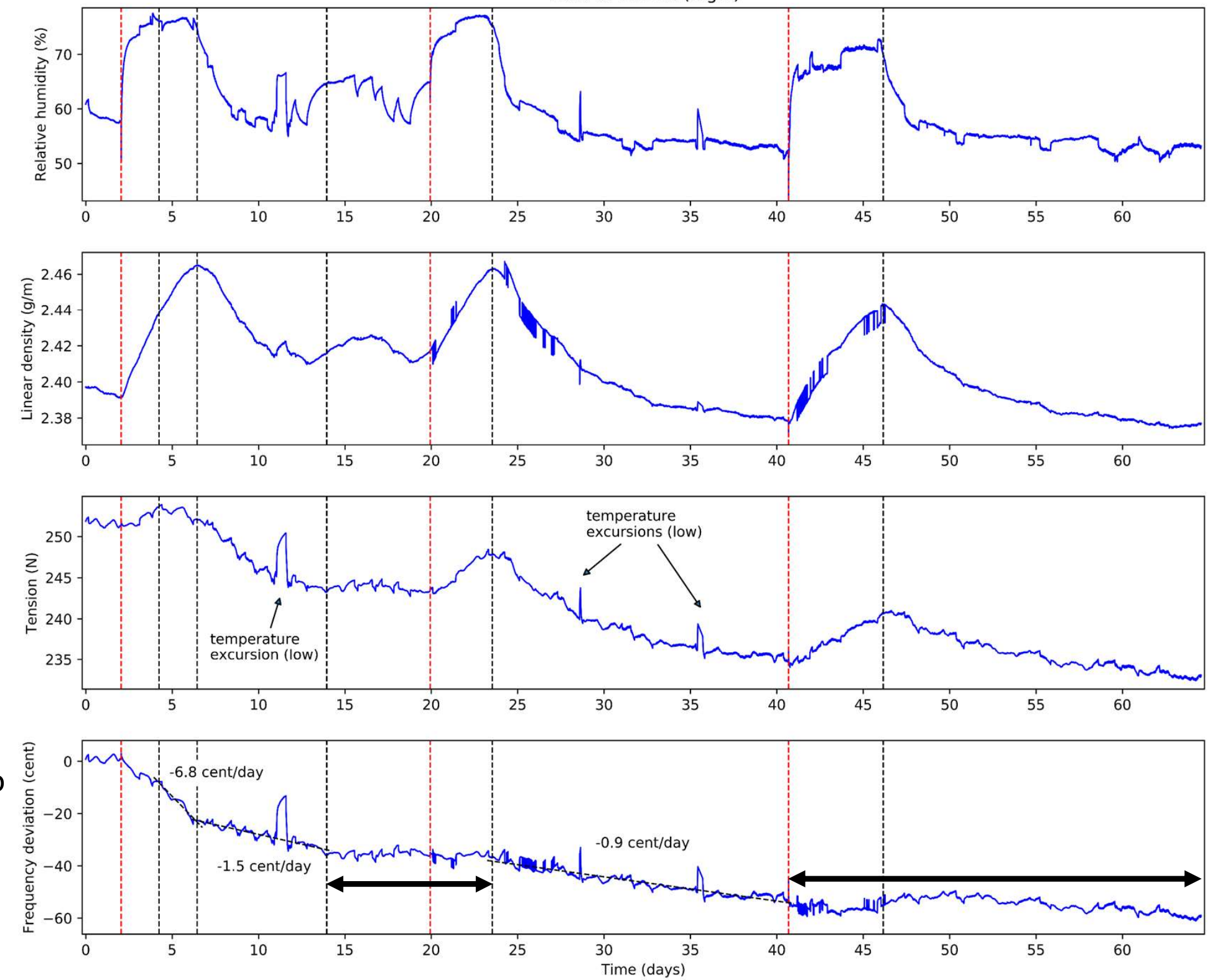

Changes in linear

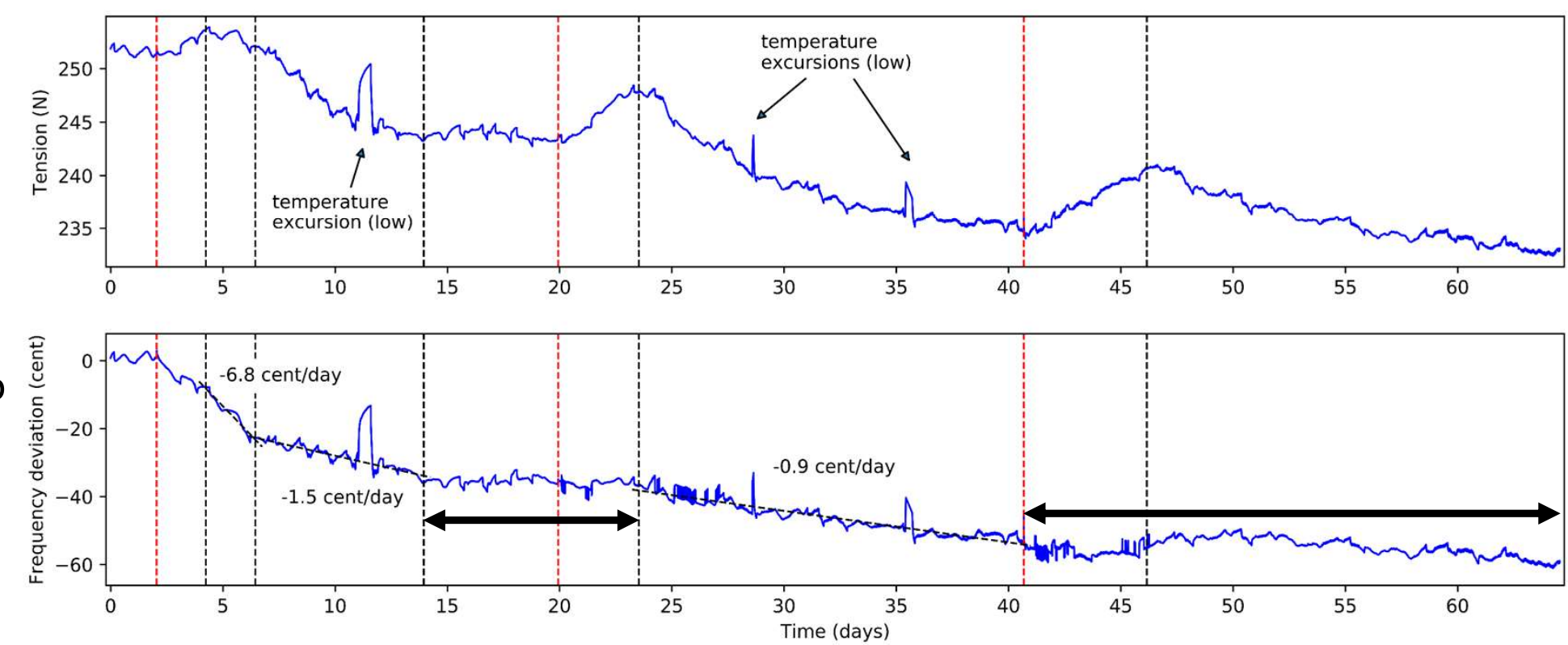
again appeared to cancel with little net effect on the frequency 
T1Aa at $324 \mathrm{~Hz}$ (Rig 1)

Twist angle $=36^{\circ}$

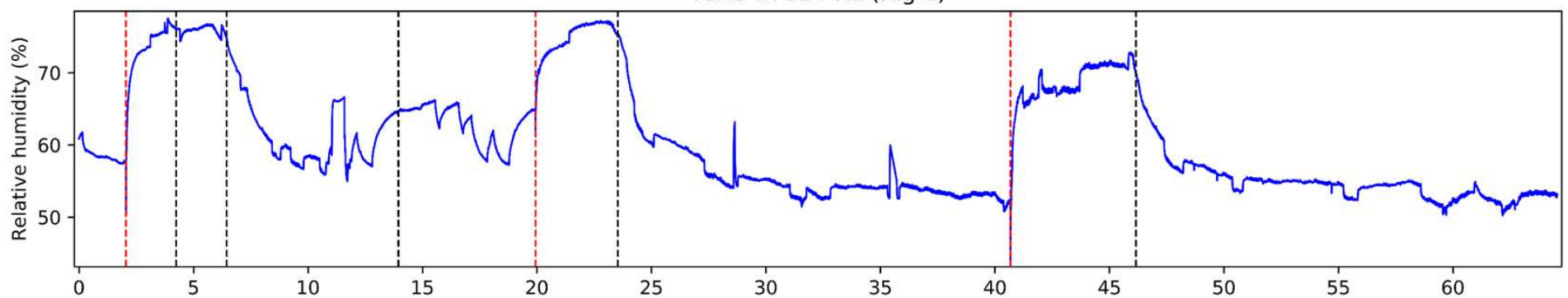

Is this really creep?

Tension fell 7\%

Frequency fell $3 \%$

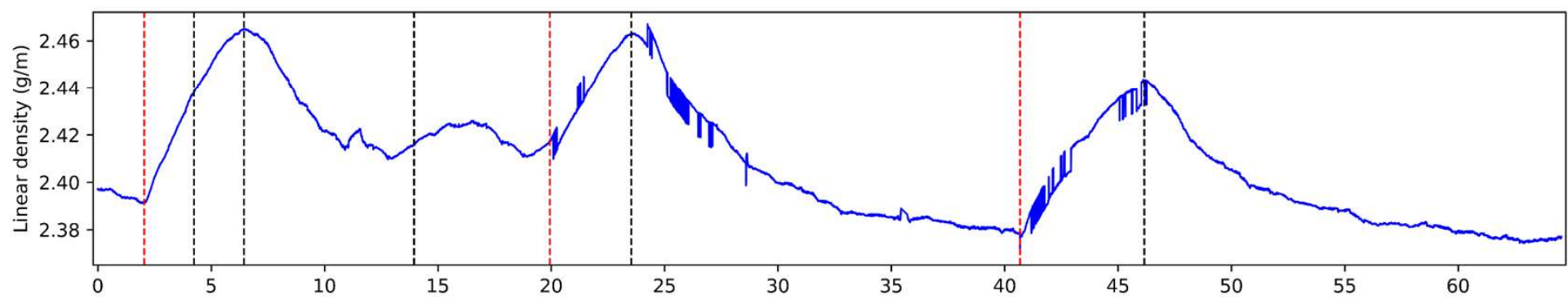

Linear density fell $1 \%$

So yes, it looks like

the string really was creeping
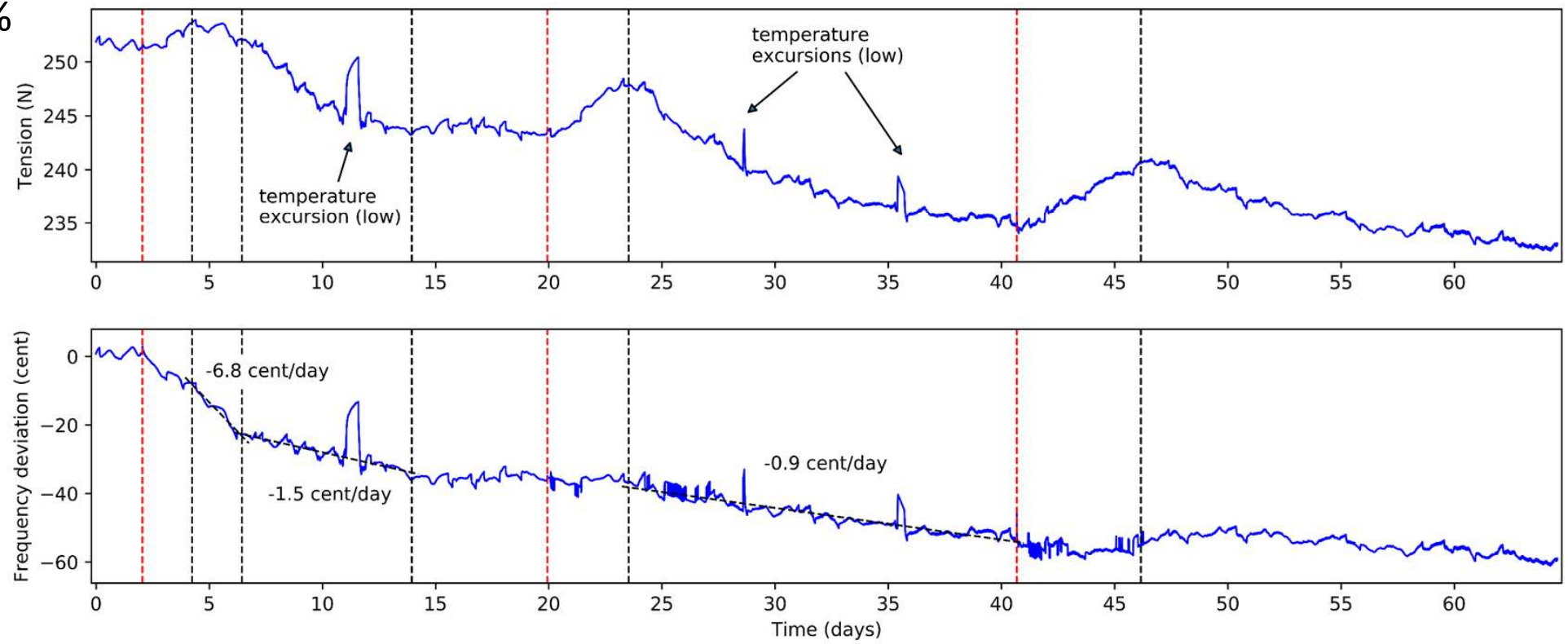


\section{Conclusions:}

- Changing the humidity level can trigger episodes of string creep.

- The string tension and linear density really do appear to be coupled in some way.

- The degree of coupling is such that there is almost no net effect on the string frequency (outside creep episodes).

- The coupling mechanism does not appear to be related to the twist angle.

- The useful life of a gut harp string may be determined as much by its propensity to creep as by its inherent yield strength. 